\title{
In-vitro characterization of canine multipotent stromal cells isolated from synovium, bone marrow, and adipose tissue: a donor-matched comparative study
}

\author{
Robert N. Bearden ${ }^{1}$, Shannon S. Huggins ${ }^{1}$, Kevin J. Cummings ${ }^{2}$, Roger Smith ${ }^{3}$, Carl A. Gregory ${ }^{4}$
} and William B. Saunders ${ }^{1 *}$

\begin{abstract}
Background: The dog represents an excellent large animal model for translational cell-based studies. Importantly, the properties of canine multipotent stromal cells (CMSCs) and the ideal tissue source for specific translational studies have yet to be established. The aim of this study was to characterize cMSCs derived from synovium, bone marrow, and adipose tissue using a donor-matched study design and a comprehensive series of in-vitro characterization, differentiation, and immunomodulation assays.

Methods: Canine MSCs were isolated from five dogs with cranial cruciate ligament rupture. All 15 cMSC preparations were evaluated using colony forming unit (CFU) assays, flow cytometry analysis, RT-PCR for pluripotencyassociated genes, proliferation assays, trilineage differentiation assays, and immunomodulation assays. Data were reported as mean \pm standard deviation and compared using repeated-measures analysis of variance and Tukey post-hoc test. Significance was established at $p<0.05$.

Results: All tissue samples produced plastic adherent, spindle-shaped preparations of cMSCs. Cells were negative for CD34, CD45, and STRO-1 and positive for CD9, CD44, and CD90, whereas the degree to which cells were positive for CD105 was variable depending on tissue of origin. Cells were positive for the pluripotency-associated genes NANOG, OCT4, and SOX2. Accounting for donor and tissue sources, there were significant differences in CFU potential, rate of proliferation, trilineage differentiation, and immunomodulatory response. Synovium and marrow cMSCs exhibited superior early osteogenic activity, but when assessing late-stage osteogenesis no significant differences were detected. Interestingly, bone morphogenic protein-2 (BMP-2) supplementation was necessary for early-stage and late-stage osteogenic differentiation, a finding consistent with other canine studies. Additionally, synovium and adipose cMSCs proliferated more rapidly, displayed higher CFU potential, and formed larger aggregates in chondrogenic assays, although proteoglycan and collagen type II staining were subjectively decreased in adipose pellets as compared to synovial and marrow pellets. Lastly, cMSCs derived from all three tissue sources modulated murine macrophage TNF-a and IL-6 levels in a lipopolysaccharide-stimulated coculture assay.

(Continued on next page)
\end{abstract}

\footnotetext{
* Correspondence: bsaunders@cvm.tamu.edu

${ }^{1}$ Department of Small Animal Clinical Sciences, College of Veterinary

Medicine and Biomedical Sciences, Texas A\&M University, College Station, TX,

USA

Full list of author information is available at the end of the article
} 
(Continued from previous page)

Conclusions: While cMSCs from synovium, marrow, and adipose tissue share a number of similarities, important differences in proliferation and trilineage differentiation exist and should be considered when selecting cMSCs for translational studies. These results and associated methods will prove useful for future translational studies involving the canine model.

Keywords: Canine, Multipotent stromal cells, Characterization, Differentiation, Immunomodulation, Synovium, Bone marrow, Adipose tissue

\section{Background}

Translation of promising findings from rodent models to humans represents a significant hurdle for cell-based therapies. For this reason, a number of large animal species have been used to bridge the gap from rodents to humans [1-4]. The canine species represents a compelling model for translational studies. When compared to rodents, dogs are large, long-lived, genetically diverse, and share many biochemical and physiological similarities with humans. Canine models have been used successfully to develop adult bone marrow transplantation, gene therapy, and allograft rejection protocols for use in humans [5-7]. Because of their response to learned behaviors such as treadmill exercise, dogs have been used to develop new therapies for cardiovascular and orthopedic diseases $[8,9]$. From a biomechanical perspective, the canine skeleton undergoes loading in a manner which approximates that of the human skeleton $[10,11]$. For these reasons, canine osteoarthritis, anterior cruciate ligament repair, meniscal injury, and nonunion fracture models are well described [12-19]. Additionally, humans often consider dogs as in-home pets, exposing both to similar environmental stimuli, which helps to eliminate variables between species [20, 21]. For many of these reasons, canine spontaneous diseases have been used to translate novel therapeutics to humans [22, 23]. Benefits of the canine translational model have been described extensively in recent review articles [24, 25].

Multipotent stromal cells (MSCs) are classically isolated from bone marrow and adipose tissues [26-32]; however, recent literature has described the isolation of MSCs from synovium [33], skeletal muscle [34], periosteum [35], and dental pulp [36]. While MSCs isolated from these diverse tissues meet established criteria for MSCs [37], cell proliferation and differentiation vary widely when assessed using established in-vitro assays. These differences may have important implications as investigators consider both the tissue source of MSCs as well as the model species for novel cell-based translational studies.

Although robust literature exists describing synovium, bone marrow, and adipose-derived MSCs in humans, rodents, and other species (a select list of seminal references is provided here) [26-28, 31, 32, 38-50], a more modest number of studies describe the isolation and invitro characterization of canine MSCs (cMSCs) from these tissues [29, 30, 34, 51-73]. Unfortunately, drawing comparisons between these studies is difficult due to donor variation, disparate isolation procedures, and the diverse culture and assessment techniques utilized by individual laboratories. Interestingly, results of several studies have demonstrated that cMSCs may respond differently to differentiation protocols established for human MSCs [34, 51, 52, 59, 61, 74-76]. These findings have led some authors to make slight modifications to traditional differentiation protocols in an attempt to improve the consistency of cMSC in-vitro differentiation $[30,34,52,53,75]$.

In addition to contributing to tissue and organ repair by homing, differentiation, and long-term engraftment, MSCs contribute to tissue repair through production of growth factors and anti-inflammatory cytokines, direct modulation of the immune system, and anti-apoptosis effects [77-84]. In a manner mirroring the human MSC literature, early cMSC characterization studies have typically focused on cell morphology, proliferation, flow cytometry, and trilineage differentiation. Several studies have also reported that canine bone marrow, adipose, and periodontal ligament-derived MSCs are capable of producing growth factors and anti-inflammatory cytokines or directly modulating leukocyte activity [66, 76, 85-89]. However, the immunomodulatory potential of synoviumderived cMSCs has yet to be examined. Moreover, immunomodulatory assays are typically not included in canine donor-matched MSC characterization studies. Thus, a comprehensive report describing the characteristics of donor-matched cMSCs isolated from synovium, bone marrow, and adipose tissues is of the utmost importance to allow investigators interested in the canine model to make informed decisions on cMSC sources for translational studies.

The objective of this study was to comprehensively characterize canine MSCs isolated from synovium, bone marrow, and adipose tissue using a donor-matched study design. Based on work in other species, we hypothesized that canine MSCs isolated from synovium, bone marrow, and adipose tissue would exhibit significant differences in isolation parameters, growth kinetics, 
colony forming unit (CFU) potential, flow cytometry profiles, trilineage differentiation, and immunomodulatory potential. The results of this study provide insight into important similarities and differences between cMSCs, and will prove useful for investigators considering the canine species for large animal translational studies.

\section{Methods}

For detailed descriptions of all procedures, please refer to Additional file 1.

\section{Tissue collection and cell isolation}

Canine synovium, marrow, and adipose tissue were obtained from four castrated male dogs and one spayed female dog during knee arthroscopy for cranial cruciate ligament rupture (Table 1).

Under general anesthesia, marrow aspirates were performed on the proximal humerus. Adipose tissue was obtained from the infrapatellar fat pad prior to arthroscope insertion. Synovium/subsynovial tissues were isolated from the femoropatellar joint during arthroscopy. Sample weights, volumes, and passage 0 (P0) cMSC yields are presented in Table 2 .

Nucleated cells were isolated from marrow using gradient centrifugation (Ficoll-Paque Plus; GE Health Care Biosciences, Piscataway, NJ, USA) as described previously [90]. Nucleated cells were isolated from adipose and synovial samples using enzymatic digestion [28]. In order to isolate P0 cMSCs, nucleated marrow cells were plated at $3 \times 10^{4}$ cells $/ \mathrm{cm}^{2}$ in $150-\mathrm{cm}^{2}$ tissue culture dishes in complete culture medium (CCM) containing aMEM, $100 \mathrm{U} / \mathrm{ml}$ penicillin, $100 \mu \mathrm{g} / \mathrm{ml}$ streptomycin (Invitrogen), and $10 \%$ premium select fetal bovine serum (Atlanta Biological, Inc., Flowery Branch, GA, USA), while nucleated cells from adipose and synovium tissue were plated at 200 cells $/ \mathrm{cm}^{2}$. Cells were incubated at 37 ${ }^{\circ} \mathrm{C}$ and $5 \%$ humidified $\mathrm{CO}_{2}$ for 24 hours. For the following 3 days, plates were washed with PBS to remove nonadherent cells followed by media exchange. Culture dishes were subsequently monitored for expansion of the P0 cMSCs with media exchange performed every other day. At $70 \%$ confluence (5-12 days), cells were lifted with $0.5 \%$ trypsin/EDTA solution (Invitrogen/ Thermo Fisher Scientific, Waltham, MA, USA), quantified, and reseeded at 100 cells $/ \mathrm{cm}^{2}$ for expansion of passage 1 cells. Media were exchanged every other day until cells were $70 \%$ confluent. Passage 1 cells were cryopreserved in $\alpha$ MEM with 5\% DMSO (Sigma-Aldrich, St. Louis, MO, USA) and 30\% FBS in preparation for subsequent experiments. With the exception of the CFU assays in which the initial nucleated cell populations were assayed (specific methods provided below), passage 1 cells were recovered via thawing, plated at 100 cells/ $\mathrm{cm}^{2}$, and expanded to $70 \%$ confluent passage 2 cells for use in experiments.

\section{CFU assay}

The CFU potential of the primary nucleated cell population was determined by plating isolated cells in triplicate on $55-\mathrm{cm}^{2}$ dishes at $4.5 \times 10^{5}$ total cells/dish for marrow tissue and $1 \times 10^{3}$ total cells/dish for synovium and adipose tissue as described previously [48, 91]. At 21 days, plates were stained with $0.3 \%$ crystal violet solution (Sigma, St. Louis, MO, USA), washed, photographed, and the colony number determined [92].

\section{RT-PCR for pluripotency-associated genes}

RT-PCR was performed as described previously [30] for canine GAPDH [93], NANOG, OCT4, and SOX2 [30]. Total RNA was isolated from passage 2 cells and cDNA was synthesized. PCR reactions $(20 \mu \mathrm{l})$ were performed and products were separated via agarose gel electrophoresis for visualization using Gel Green (Biotium, Hayward, CA, USA).

\section{Flow cytometry}

Passage 2 cMSCs were analyzed with commercially available antibodies, acquired from AbD Serotec (CD9, CD34, CD44, CD45, CD90; Raleigh, NC, USA), Santa Cruz (CD105; Santa Cruz, CA, USA), and R\&D Systems (STRO-1; Minneapolis, MN, USA) using a FACSCalibur flow cytometer (BD Biosciences, San Jose, CA, USA), CellQuest acquisition software (BD Biosciences), and FlowJo analysis software (TreeStar Inc., Ashland, OR, USA).

Table 1 Signalment, body weight, and body condition score of canine donors

\begin{tabular}{lllcll}
\hline Donor & Age (years) & Sex & Body weight $(\mathrm{kg})$ & BCS $(1-9)^{\text {a }}$ & Breed \\
\hline 1 & 2 & MC & 29.3 & 4 & Catahoula \\
2 & 6 & MC & 71.7 & 8 & Newfoundland \\
3 & 3 & MC & 21.4 & 4 & Mix Breed \\
4 & 3 & MC & 39.4 & 6 & Labrador Retriever \\
5 & 5 & FS & 43.5 & 6 & German Shepherd
\end{tabular}

Age, sex, body weight (kilograms), body condition score, and breed of the five canine donors enrolled in this study $M C$ male, castrated; FS female, spayed; $B C S$ body condition score

${ }^{\mathrm{a}} \mathrm{BCS}$ is a measure of obesity, with 1 representing an extremely thin animal, 4-6 representing an ideal body condition, and 9 representing morbid obesity 
Table 2 Sample yield, colony forming unit potential, and passage 0 yield from five canine donors

\begin{tabular}{|c|c|c|c|c|c|}
\hline Source & Sample weight (g) & $\begin{array}{l}\text { Nucleated cell number } \\
\left(\times 10^{3} \text { cells }\right) / \text { gram of tissue }\end{array}$ & $\begin{array}{l}\text { Colony number/nucleated } \\
\text { cells (CFU \%) }\end{array}$ & $\begin{array}{l}\text { Mean colony } \\
\text { area }\left(\mathrm{mm}^{2}\right)\end{array}$ & $\begin{array}{l}\text { PO CMSC } \\
\left(\times 10^{6}\right) / \text { plate }\end{array}$ \\
\hline Synovium & $0.24 \pm 0.01$ & $46.6 \pm 62.80$ & $6.48 \pm 3.49$ & $0.28 \pm 0.03$ & $3.13 \pm 3.64$ \\
\hline Marrow & $4.20 \pm 0.80$ & $18.70 \pm 28.10$ & $0.01 \pm 0.01$ & $0.26 \pm 0.13$ & $0.48 \pm 0.4$ \\
\hline Adipose & $0.31 \pm 0.10$ & $12.90 \pm 12.00$ & $2.63 \pm 2.17$ & $0.26 \pm 0.13$ & $2.76 \pm 5.45$ \\
\hline
\end{tabular}

All data reported as mean \pm standard deviation

Nucleated cells were isolated using Ficoll ${ }^{\mathrm{TM}}$ centrifugation (marrow) or enzymatic digestion (synovium, adipose) and plated at clonal density. Tissue sample weights and the number of nucleated cells recovered from tissue samples adjusted per gram of tissue are presented. After isolation, the colony forming unit (CFU) potential of primary cell populations for all 15 donors was performed: $1 \times 10^{3}$ total cells (synovium and adipose) or $4.5 \times 10^{5}$ total cells (marrow) were seeded on $55-\mathrm{cm}^{2}$ plates and incubated for 21 days. Plates were stained with $0.3 \%$ crystal violet and the colony number and surface area (mm ${ }^{2}$ ) were determined for each plate. Using separate MSC isolation plates, the numbers of plastic-adherent canine multipotent stromal cells (cMSCs) recovered at passage $0(P 0)$ after 5-12 days in culture are reported as number of cMSCs/isolation plate

\section{Proliferation assays}

\section{Short-term proliferation}

To compare the short-term proliferation of synovium, marrow, and adipose cMSCs, cells were plated at 100 cells $/ \mathrm{cm}^{2}$ in triplicate wells on 12-well tissue culture plates in CCM. Cells were washed with PBS, fixed in $500 \mu \mathrm{l}$ of DNA quantification buffer at 24-hour intervals for 10 days, and quantified by fluorescence DNA incorporation assay as described previously [94].

\section{Long-term proliferation}

To compare the proliferation of cMSCs over multiple passages, cells were plated in triplicate at 100 cells $/ \mathrm{cm}^{2}$ in CCM with media exchange every other day. After 5 days, cells were trypsinized, counted manually, and replated at 100 cells $/ \mathrm{cm}^{2}$. This process was repeated for a total of five cell passages ( 25 cumulative days in culture). At each passage, cell yield per plate was determined using a hemocytometer and trypan blue exclusion ( $n=3$ plates/cell preparation) and data were reported as the number of population doublings per passage as described previously [95].

\section{Adipogenesis}

Canine MSCs were plated at $2 \times 10^{4}$ cells $/ \mathrm{cm}^{2}$ in 12-well plates ( $n=4$ wells/condition) and were treated with control medium (CCM) or modified adipogenic medium ( $\alpha M E M$ containing $1 \mathrm{nM}$ dexamethasone (Sigma), $5 \mathrm{mM}$ rosiglitazone (Sigma), $50 \mathrm{mM}$ pantothenate (Enzo Life Sciences, Farmingdale, NY, USA), $10 \mathrm{mM}$ insulin (Sigma), $30 \mathrm{mM}$ biotin (Enzo), $50 \mathrm{mM}$ isobutylmethylxanthine (Sigma), and 10\% serum (5\% FBS, 5\% rabbit serum; Atlanta Biological)) [30, 34, 53, 74, 96-98]. After 21 days, cells were washed, fixed in $10 \%$ neutral buffered formalin, and stained with $0.5 \%$ Oil Red O (Sigma). Cells were photographed prior to extraction of Oil Red O for quantification as described previously [96].

Early assay of osteogenesis-alkaline phosphatase activity Canine MSCs were plated at $5 \times 10^{3}$ cells $/ \mathrm{cm}^{2}$ in 12 -well plates ( $n=3$ wells/condition) and were treated with control medium (CCM) or osteogenic basal medium $(\mathrm{OBM})$ ( $\alpha \mathrm{MEM}$ containing $5 \% \mathrm{FBS}, 10 \mu \mathrm{g} / \mathrm{ml}$ betaglycerophosphate (Sigma), $50 \mathrm{mg} / \mathrm{ml}$ ascorbate-2phosphate (Sigma)) optimized for cMSCs [94]. In addition, cells were treated with OBM supplemented with 50 or $100 \mathrm{ng} / \mathrm{ml}$ of recombinant human bone morphogenic protein-2 (rhBMP-2; R\&D Systems) [52, 94]. After 7 days, alkaline phosphatase (ALP) activity was determined as described previously [94]. ALP activity of each well was normalized to the number of cells per well using DNA quantification.

\section{Late-stage assay of osteogenesis-Alizarin Red stain mineralization}

Detachment of high-density monolayers from polystyrene tissue culture plastic in late-stage mineralization assays is a phenomenon that is not uncommon in cMSC mineralization assays. We identified this phenomenon in our early workings with cMSCs (unpublished observations) and this problem has been reported in prior cMSC literature [30, 34, 51, 52, 61, 74, 75]. In order to prevent monolayer detachment, cMSCs were plated in CCM at $2 \times 10^{4}$ cells $/ \mathrm{cm}^{2}$ in 12 -well plates $(n=4$ wells/ condition). Prior to plating, the periphery of each well was scored mechanically using a sterile stone dremel bit and associated hand chuck in order to create a circular etching around the well margin. Wells were coated with human fibroblast-derived fibronectin (Sigma) at $5 \mathrm{mg} / \mathrm{ml}$ in PBS for 30 minutes at $37^{\circ} \mathrm{C}$. Excess fibronectin was removed and cells were seeded in each well. The following day, cells were treated with CCM, OBM, or OBM supplemented with $200 \mathrm{ng} / \mathrm{ml} \mathrm{rhBMP}-2$. Media were exchanged twice weekly. After 7 days, $1 \mathrm{nM}$ dexamethasone was added to OBM and OBM + BMP-2 wells, creating osteogenic differentiation media (ODM) to induce mineralization [94, 97]. At 21 days, cells were washed with PBS and fixed in $500 \mu \mathrm{l}$ of $10 \%$ neutral buffered formalin prior to staining in $40 \mathrm{nM}$ Alizarin Red stain (ARS; Sigma) to visualize calcium deposition within osteogenic monolayers. Wells were photographed prior to extraction of ARS for semi-quantification via 
spectrophotometry using an acetic acid extraction technique as described previously [94].

\section{Chondrogenesis}

Micromass cultures of cMSCs were generated from $5 \times 10^{5}$ cells using techniques described previously [96, 97, 99]. Chondrogenesis was assessed using digital morphometry to quantify the pellet size, toluidine blue histology, and collagen type II immunohistochemistry. For histologic studies, formalin-fixed pellets were sectioned in paraffin, processed by standard methods, and stained with $1 \%$ toluidine blue/sodium borate. Visualization of collagen type II expression was achieved by immunohistochemistry using the Vectastain ABC Kit (Vector Laboratories Inc., Burlingame, CA, USA) and a commercially available rabbit anti-collagen type II antibody (Abcam, Cambridge, MA, USA) as described previously [100, 101].

\section{Immunomodulation}

To assess macrophage-mediated immunomodulation, mouse macrophage cells (RAW 264.7 cell line, American Type Culture Collection TIB-71) were seeded at $1 \times 10^{4}$ cells $/ \mathrm{cm}^{2}$ in 12-well plates in CCM. After 24 hours, cMSCs were titrated $\left(1 \times 10^{3}, 1 \times 10^{4}, 2.5 \times 10^{4}\right.$, and $5 \times$ $10^{4}$ cells/well $)$ to initiate a 24 hour coculture $(n=3$ replicates/cMSC dosage). Lipopolysaccharide (LPS) (Escherichia coli 055:B5 strain; Sigma) was introduced to each well at $0.5 \mu \mathrm{g} / \mathrm{ml}$ to induce macrophage activation. Cocultures were allowed to respond for 18 hours and conditioned media were collected and stored at $-20{ }^{\circ} \mathrm{C}$. Media were thawed on ice and analyzed for murine TNF$\alpha$ (DY410-05) and IL-6 (DY406-05) protein concentrations via enzyme-linked immunosorbent assay (ELISA) according to the manufacturer's protocol (R\&D Systems).

\section{Statistical analysis}

Descriptive statistics were generated using GraphPad Prism 6.0 (GraphPad Software, La Jolla, CA, USA) and reported as mean \pm standard deviation (SD). Data were imported into a commercial statistical software program (SAS version 9.4; SAS Institute Inc., Cary, NC, USA) for inferential statistics. Repeated-measures ANOVA was used to determine whether each parameter differed significantly by tissue type and treatment group, as appropriate, with donor dog regarded as a random effect. The Tukey method was used to adjust for multiple pairwise comparisons. For all analyses, $p<0.05$ was considered significant.

\section{Results}

\section{Cell isolation and CFU potential}

Mononuclear cells were successfully isolated from each donor and tissue sample (Table 2). Synovium $\left(46.6 \times 10^{3}\right.$ $\pm 62.8 \times 10^{3}$ cells/g of tissue) provided greater numbers of nucleated cells when compared to the marrow $(18.7 \times$ $10^{3} \pm 28.1 \times 10^{3}$ cells $/ g$ of tissue) and adipose tissue $\left(12.9 \times 10^{3} \pm 12.0 \times 10^{3}\right.$ cells $/ g$ of tissue $)$, although these differences were not significant $(p=0.2)$. In addition, we were unable to detect a difference in the number of total nucleated cells isolated from marrow or adipose tissue $(p=0.8)$ (Fig. 1a, Table 2). After 5-14 days of culture, cMSCs were identified in primary expansion plates as plastic-adherent, spindle-shaped cells (Fig. 1b). All primary nucleated cell populations obtained from the 15 tissue samples exhibited some degree of colony forming unit (CFU) potential. Using repeated-measures ANOVA, significant differences were observed in the CFU potential between the three tissues $(p<0.0001)$, with synovium $(6.48 \pm 3.49 \%)$ and adipose $(2.63 \pm 2.17 \%)$ tissue exhibiting markedly higher CFU potential when compared to marrow tissue $(0.009 \pm 0.01 \%)$. Specifically, the CFU potential of synovium cMSCs was significantly greater than that of both adipose-derived $(p<0.001)$ and marrowderived $(p<0.0001)$ cells, whereas the CFU potential of adipose cMSCs was significantly greater than that of marrow-derived cells $(p<0.01)$ (Fig. 1c, d, Table 2). These CFU values are consistent with studies reporting CFU potential of human MSCs derived from synovium, marrow, and adipose tissue.

\section{Cell surface marker expression}

A flow cytometry panel capable of cross-reacting with canine isoforms of cell surface markers was used to characterize each preparation of cMSCs. Representative flow cytometry results for a preparation of MSCs derived from canine bone marrow are shown in Fig. 2. The mean \pm SD antibody labeling results for all 15 preparations of cMSCs is provided in Additional file 2. All cMSCs were negative for the leukocyte markers CD34 and CD45. Cells were consistently positive for CD9, CD44, and CD90. Interestingly, there was variable staining for CD105 (Endoglin), with synovium (46.16 \pm $21.78 \%)$ and adipose $(59.84 \pm 15.57 \%)$ cMSCs exhibiting higher percentage positive staining cells when compared to marrow cMSCs $(17.12 \pm 8.85 \%)$. Additionally, cMSCs were negative for STRO-1, despite confirming crossreactivity of the commercially available STRO-1 antibody on canine peripheral blood (data not shown).

\section{Pluripotency-associated gene expression}

Reverse-transcription PCR was used to evaluate all cell preparations for the canine isoforms of the pluripotency associated transcription factors NANOG, OCT4, and $S O X 2$ [30]. All cMSC preparations were positive for each gene (Fig. 3). 

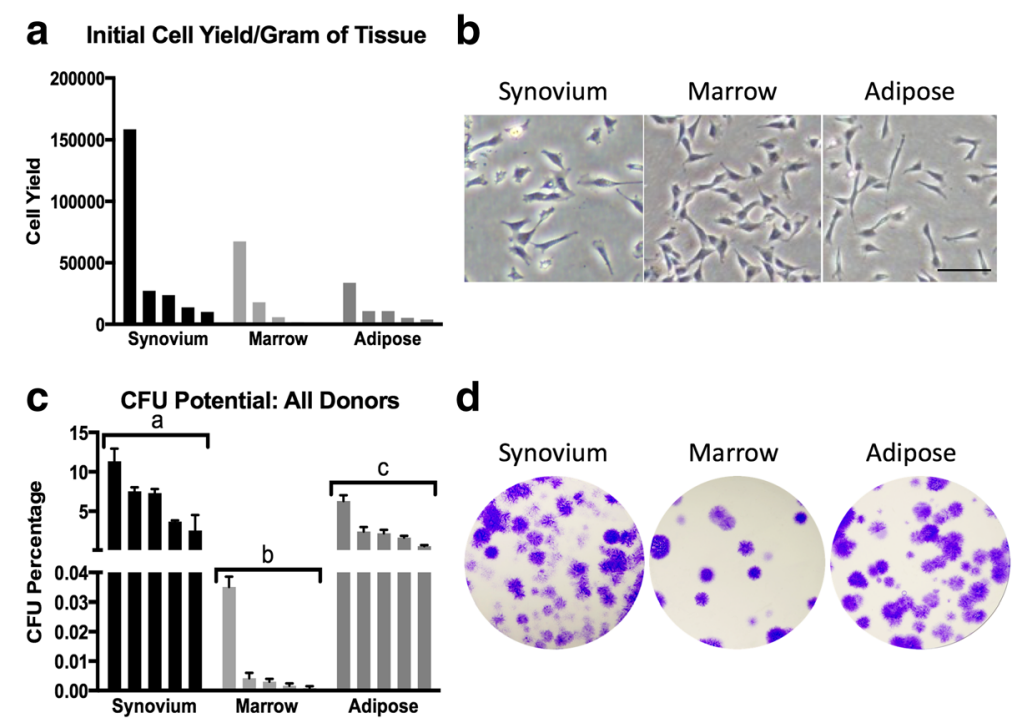

Fig. 1 Initial cell isolation and colony forming unit (CFU) potential. Synovium, marrow, and adipose tissues were obtained from five canine donors presenting for rupture of the cranial cruciate ligament. Cells were isolated using Ficoll ${ }^{\mathrm{TM}}$ centrifugation (marrow) or enzymatic digestion (synovium, adipose) and plated at clonal density. a Initial nucleated cell yield for all 15 donors, normalized to tissue weight. b Representative 10x objective phase-contrast microscopy images 7 days post isolation (bar $=100 \mu \mathrm{m})$. c CFU potential of primary cell populations for all 15 donors: $1 \times 10^{3}$ total cells (synovium and adipose) or $4.5 \times 10^{5}$ total cells (marrow) were seeded on $55-\mathrm{cm}^{2}$ plates and incubated for 21 days. Plates were stained with $0.3 \% \mathrm{crystal}$ violet and colony counts were performed on each plate. CFU potential is defined as the number of colonies present divided by total number of seeded cells, expressed as a percentage of the total seeded cells. Data reported as mean $\pm \mathrm{SD}(n=3$ plates/tissue). $a, b, c$ denote significant differences between tissue sources of $\mathrm{CMSCS}(p<0.0001)$. $\mathbf{d}$ Photographs of CFU plates from a single representative donor. For $\mathbf{a}$ and $\mathbf{c}$, data are reported in descending order for each tissue type

\section{Proliferation assays}

Both short-term and long-term proliferation assays were used to assess the proliferation of donor-matched cMSCs derived from synovium, marrow, and adipose tissues. In short-term assays, there were significant differences in proliferation between synovium, marrow, and adipose cMSCs $(p<0.01)$. Consistent with a previous study evaluating human MSCs [28], adipose and synovium cMSCs proliferated more rapidly than marrow cMSCs. A proliferation curve from a representative donor is shown (Fig. 4a). Scatter plots reporting the number of recovered cells at day 5 and day 10 for all 15 cMSC isolates are also provided (Fig. 4b). Using repeated-measures ANOVA, adipose cMSC proliferation was significantly greater than that of marrow $(p<0.01)$ and synovium $(p<0.05)$. While synovium cMSCs tended to proliferate more rapidly than marrow cMSCs, differences were not significant in the short-term assay $(p=0.2)$. These results indicate that when using a donor-matched study design, the tissue source of cMSCs affects short-term proliferation of these cells.

In long-term assays, the tissue source of cMSCs had a significant effect on the number of recovered cells over the five-passage, 25-day time course $(p<0.0001)$ (Fig. 4c, d). As reported previously in other species, population doubling decreased significantly with sequential passaging $(p<0.0001)$. Results for a representative donor are shown in Fig. 4c. The mean population doubling at passages 1 and 5 for all cMSC preparations is also provided (Fig. 4d). Using repeated-measures ANOVA, population doubling of both adipose $(p<0.0001)$ and synovium $(p<0.0001)$ cMSCs was significantly greater than that of marrow cMSCs across all passages. Additionally, the population doubling of adipose and synovium cMSCs was significantly different $(p=0.02)$. These results demonstrate the greater proliferation abilities of adipose and synovium cMSCs as well as the finite proliferation of cMSCs derived from all three tissues.

\section{Trilineage differentiation \\ Adipogenesis}

Adipogenesis was evaluated at 21 days by both visual assessment of lipid vacuole accumulation and quantification of Oil Red $\mathrm{O}$ staining. All cMSCs underwent varying degrees of adipogenesis, with increased vacuole formation and Oil Red $\mathrm{O}$ staining when compared to control (CCM). Oil Red O accumulation for a representative donor is shown in Fig. 5a. Morphologically, synovium and adipose cMSCs produced medium to large, grape-like vacuoles, whereas marrow cMSCs produced small, diffuse vacuoles. When evaluating Oil Red $\mathrm{O}$ extraction for Fig. 5a, significant differences were detected (Fig. 5b). Oil Red $\mathrm{O}$ extraction values for all $15 \mathrm{cMSC}$ preparations are provided (Fig. 5c). Using repeated-measures ANOVA, there 


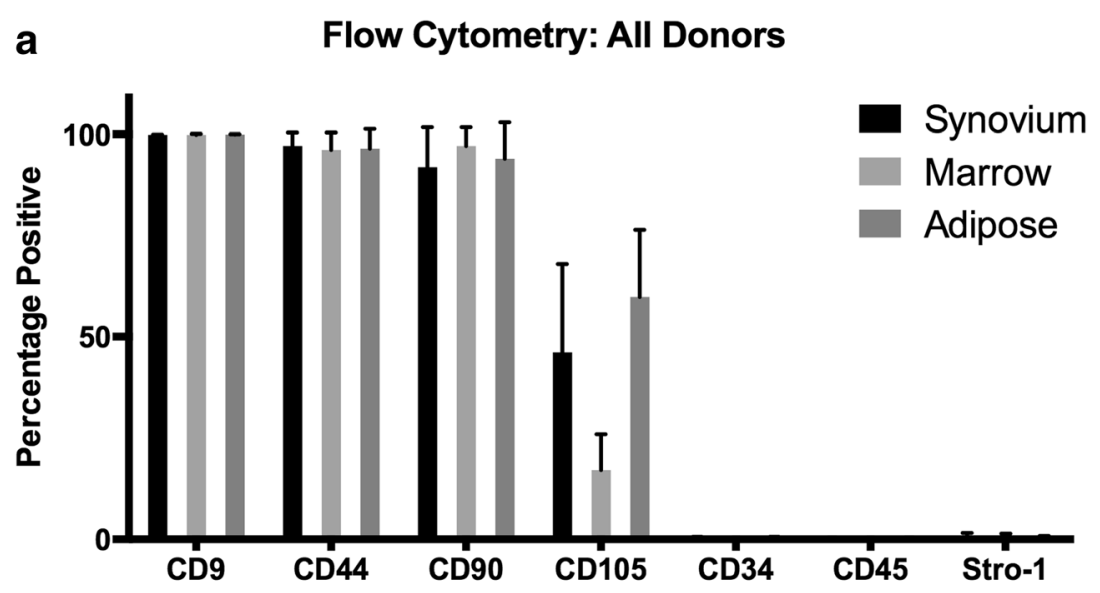

b
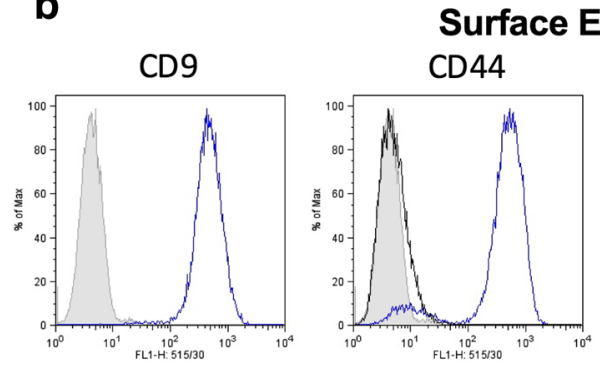

Surface Epitope

$\mathrm{CD} 34$

CD45
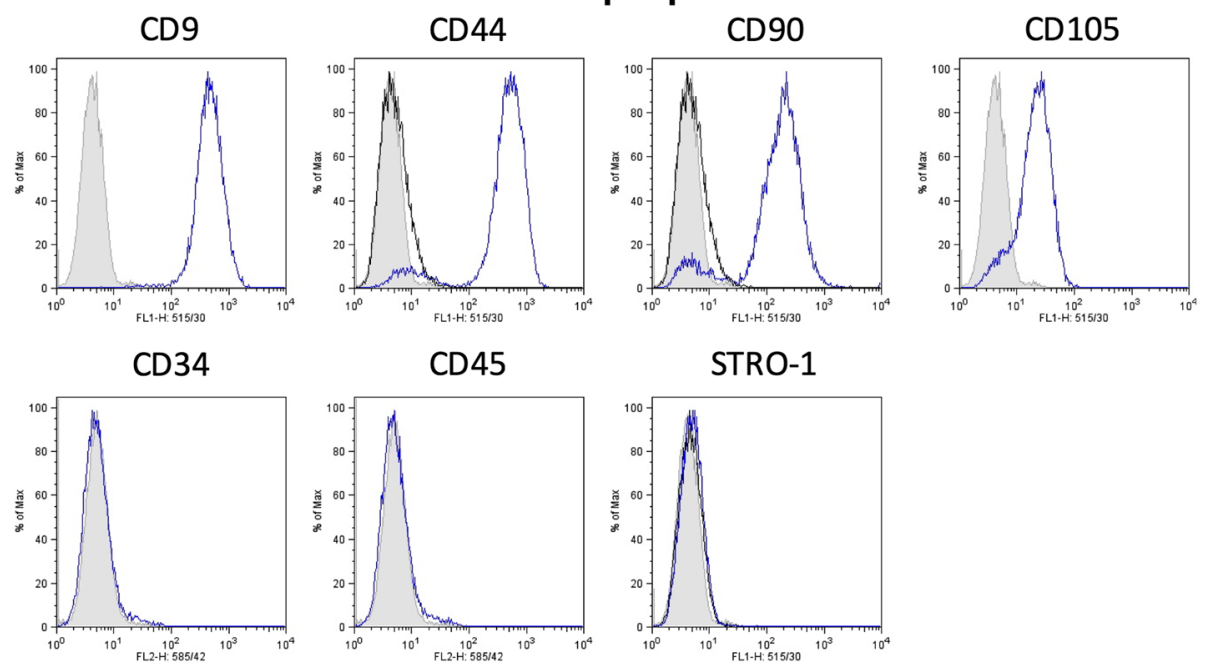

STRO-1

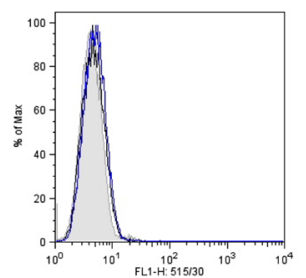

Fig. 2 Flow cytometry for synovium, marrow, and adipose cMSCs. a Percentage of positive cells reported as mean \pm SD for synovium, marrow, and adipose cMSCs isolated from five canine donors. b Representative histograms demonstrating positive and negative staining of marrow cMSCs from a single donor

was a significant increase in Oil Red $\mathrm{O}$ extraction for cMSCs treated with adipogenic media as compared to CCM control wells $(p<0.0001$, results not shown). In addition, there were significant differences in Oil Red O extraction based on tissue source of the cMSCs $(p<0.001)$. Adipose cMSCs had significantly greater Oil Red $\mathrm{O}$ extraction values across all donors when compared to marrow $(p<0.01)$ and synovium $(p<0.001)$ cMSCs; however, we were unable to detect a difference in Oil Red O extraction between synovium and marrow cMSCs $(p=0.4)$. These results indicate that while synovium, marrow, and adipose cMSCs are capable of undergoing adipogenesis, adipose cMSCs are superior in their adipogenic ability.

\section{Early osteogenesis-ALP activity}

Early osteogenesis was evaluated at 7 days using the ALP activity assay. In contrast to MSCs from other species, it has been reported previously that cMSCs require osteogenic medium supplemented with BMP-2 in order to exhibit robust ALP activity $[52,75]$. In order to confirm this unique property of cMSCs isolated from synovium, marrow, and adipose tissue, ALP activity assays were performed on all 15 cMSC isolates after initiation of osteogenesis with OBM or OBM containing 50 or $100 \mathrm{ng} / \mathrm{ml} \mathrm{rhBMP-2}$. Over the 20-minute kinetic assay, there was no detectable ALP activity in cMSCs treated with CCM or OBM (a medium known to induce robust ALP activity in human MSCs); however, OBM containing rhBMP-2 induced a dose-dependent increase in ALP activity. Results from a representative donor (marrow cMSCs) are shown in Fig. 6a. ALP activity, normalized to a per-cell basis using DNA quantification, for synovium, marrow, and adipose cMSCs from the donor presented in Fig. 6a is also provided (Fig. 6b). 


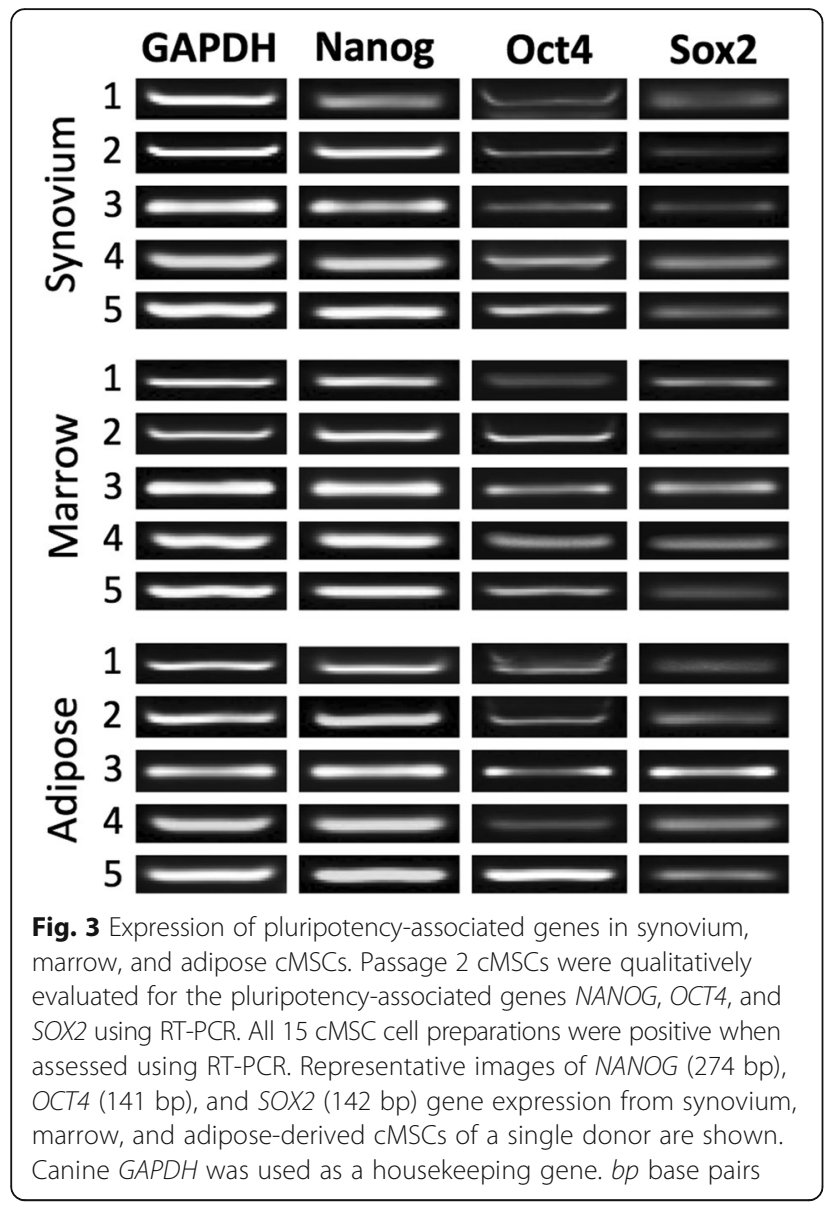

ALP activity values for all 15 cMSCs are shown in Fig. 6c. Using repeated-measures ANOVA, there were significant differences in ALP activity based on media condition $(p<0.0001)$ as well as the cMSC tissue source $(p<0.01)$. There was no detectable difference in ALP activity between cMSCs cultured in CCM or OBM ( $p=$ 0.999). ALP activity was significantly increased for cMSCs treated with OBM $+50 \mathrm{ng} / \mathrm{ml}$ rhBMP-2 $(p<$ $0.001)$ and $\mathrm{OBM}+100 \mathrm{ng} / \mathrm{ml}$ rhBMP-2 $(p<0.0001)$ when compared to CCM or OBM. Additionally, cMSCs treated with $\mathrm{OBM}+100 \mathrm{ng} / \mathrm{ml}$ rhBMP-2 exhibited significantly higher ALP activity as compared to cMSCs treated with $\mathrm{OBM}+50 \mathrm{ng} / \mathrm{ml}$ rhBMP-2 $(p<0.001)$. When considering the cMSC tissue source, marrowderived cMSCs exhibited significantly greater ALP activity when compared to adipose cMSCs $(p<0.001)$ and synovium cMSCs $(p<0.05)$, while no significant difference in ALP activity was observed between synovium and adipose cMSCs $(p=0.1)$. Collectively, these data demonstrate that cMSCs require exogenous BMP-2 to exhibit detectable ALP activity, and that rhBMP-2 supplementation drives ALP activity in a dose-dependent manner. Moreover, while synovium and marrow cMSCs from individual donors respond robustly to $\mathrm{OBM}+$ rhBMP-2, donor-matched adipose-derived cMSCs exhibit markedly reduced early osteogenic differentiation when assessed by the ALP activity assay.

\section{Late-stage osteogenesis-ARS mineralization assay}

Late-stage, biomineralizing osteogenesis was evaluated at 21 days with visual staining of calcium deposits within monolayers and semi-quantification of extracted ARS. All cMSCs underwent varying degrees of osteogenesis as assessed by ARS binding (Fig. 7). ARS results for a representative donor are shown in Fig. 7a. While ARS did not accumulate in control wells (CCM) or in wells treated with ODM lacking BMP-2 (results not shown), ARS accumulation was robust in synovium, marrow, and adipose cMSCs treated with ODM + $200 \mathrm{ng} / \mathrm{ml} \mathrm{rhBMP}-$ 2. Semi-quantification of ARS extraction for this donor is shown in Fig. 7b. There was a significant increase in ARS extraction for all three tissues when compared to control (CCM), with synovium and adipose cMSCs exhibiting significantly greater ARS extraction when compared to marrow cMSCs for this individual donor.

ARS extraction values for all $15 \mathrm{cMSC}$ cell lines are provided (Fig. 7c). Using repeated-measures ANOVA, there was a significant increase in ARS extraction in cMSCs treated with ODM $+200 \mathrm{ng} / \mathrm{ml}$ rhBMP-2 as compared to control $(p<0.0001)$. However, when accounting for variation across donors, there was no significant difference in ARS extraction based on the tissue source of the cMSCs $(p=0.5)$.

\section{Chondrogenesis}

Each of the 15 preparations of cMSCs underwent condensation and adopted a spherical translucent appearance in response to chondrogenic differentiation medium. Furthermore, cell pellets increased in size over 21 days. Results from a representative donor are shown in Fig. 8a,b. Synovium and adipose cMSCs produced larger pellets as compared to marrow cMSCs. Marrow cMSCs were smaller in size and consistently displayed deep staining for toluidine blue and collagen type II (Fig. 8a). Although adipose cMSCs produced the largest pellets for this donor, toluidine blue and collagen type II immunohistochemistry staining was apparent within the center of the pellet, whereas much of the periphery of the pellet exhibited limited toluidine blue or collagen type II staining. The synovial pellet for this same donor demonstrated more uniform collagen type II staining throughout the pellet, while toluidine blue staining was limited to the center of the structure. These subjective appearances were consistent across the 15 preparations of cMSCs.

Digital morphometric results for all $15 \mathrm{cMSC}$ isolates treated with chondrogenic differentiation medium for 

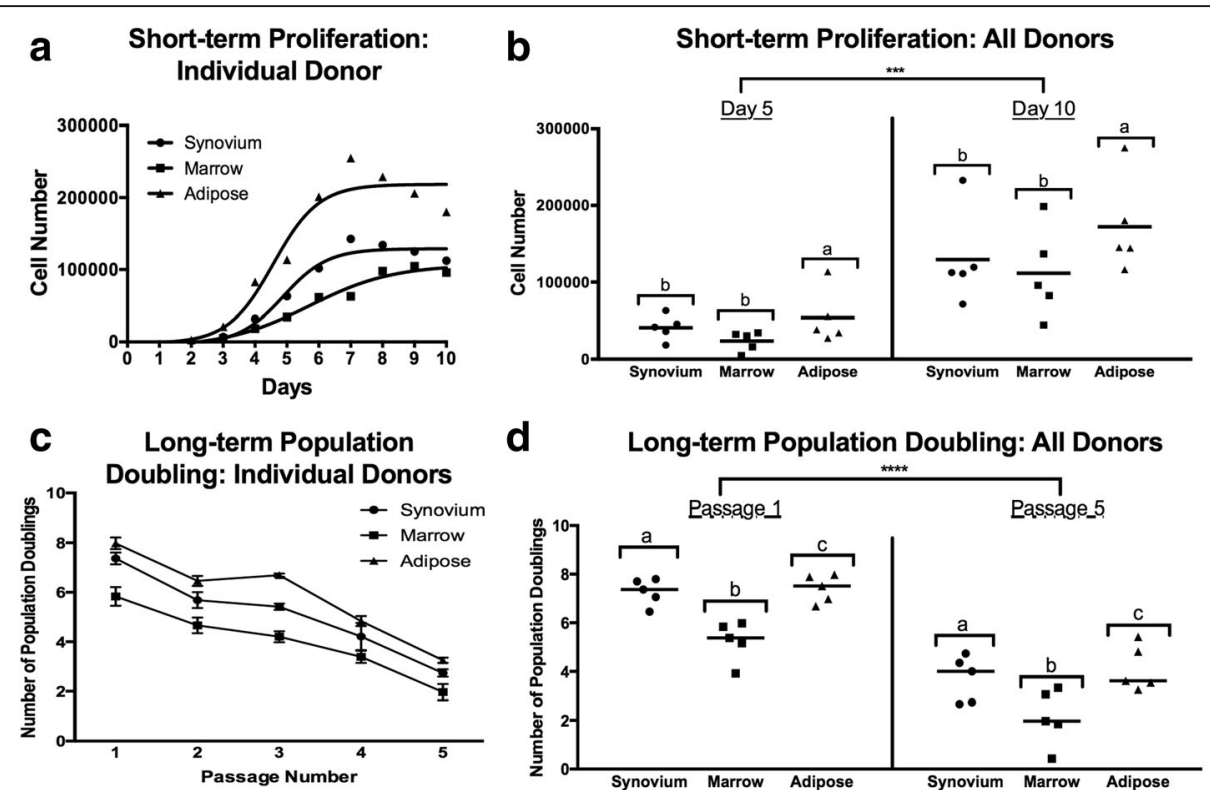

Fig. 4 Short-term and long-term proliferation of cMSCs. Passage 2 cMSCs were seeded at $100 \mathrm{cell} / \mathrm{s} / \mathrm{cm}^{2}$ in CCM on 12 -well plates $(n=3$ wells/cell preparation) with media exchange every other day. Mean cell number determined daily for 10 consecutive days using DNA quantification. a Mean short-term proliferation of a representative donor, demonstrating higher proliferation rates of adipose and synovium cMSCs. b Scatter plot demonstrating the number of cMSCs for all 15 cell preparations at days 5 and 10. Each data point represents the cell number for an individual cMSC preparation (bar = mean cell yield across the five donors). Long-term proliferation was determined over a five-passage, 25-day time course as described in the Methods section. c Population doubling (mean \pm SD) of a representative donor, demonstrating increased doubling rate of adipose and synovium CMSCs, particularly at passages 1-3. d Population-doubling scatter plot for all 15 cMSC preparations at passages 1 and 5. Each data point represents the population-doubling rate for an individual cMSC preparation (bar = mean population doubling rate across the five donors). Note: $\mathbf{b}, \mathbf{d}$ significant differences in cell number: ${ }^{* * *} p<0.001,{ }^{* * *} p<0.0001 . a, b, c$ denote significant differences between tissue sources $(p<0.05)$

21 days are shown in Fig. 8c. Using repeated-measures ANOVA, there was a significant difference in pellet size based on the cMSC tissue of origin $(p<0.01)$. Both adipose $(p<0.001)$ and synovium $(p<0.01)$ cMSC pellets were significantly larger than marrow cMSC pellets. We were unable to detect a significant difference in pellet size when comparing synovium or adipose cMSCs $(p=0.2)$. As already described, when subjectively assessing toluidine blue and collagen type II stain accumulation, marrow cMSC pellets exhibited deeper and more uniformly consistent staining compared to synovium and adipose-derived cMSC pellets. Synovium cMSCs exhibited increased collagen type II staining throughout the sections, whereas adipose-derived cMSC collagen type II staining was markedly reduced in the periphery of each section.

\section{Immunomodulation}

To assess the immunomodulatory potential of cMSCs, we established macrophage and cMSC coculture experiments in which a murine macrophage cell line (RAW 264.7 cell line) was cultured alone or in combination with increasing numbers of cMSCs. Cultures were challenged with LPS and assessed for secreted murine TNF- $\alpha$ and IL-6 concentrations were determined in conditioned media to measure inflammatory responses by the RAW cells and also to assess whether cMSCs could affect the production of these two cytokines. The concentration of TNF- $\alpha$ detected in a representative coculture experiment is reported (Fig. 9a). As has been described in other species $[102,103]$, cMSC coculture resulted in a dose-dependent decrease in the concentration of murine TNF- $\alpha$. In order to make direct comparisons across all $15 \mathrm{cMSC}$ preparations, the measured concentrations of TNF- $\alpha$ were normalized to the positive control (murine cells alone stimulated with LPS) for each assay and reported as the percentage TNF- $\alpha$ relative to control (Fig. 9b).

The relative concentrations of TNF- $\alpha$ for all 15 cMSC coculture experiments are shown in Fig. 9c. Using repeated-measures ANOVA, there were significant differences in TNF- $\alpha$ based on the number of cMSCs present within the cocultures $(p<0.0001)$, whereas the tissue source of cMSCs had no effect on TNF- $\alpha(p=0.5)$. TNF- $\alpha$ concentrations were significantly decreased in cocultures containing $5 \times 10^{4}$ cells $(p<0.0001)$ and $2.5 \times 10^{4}$ cells $(p<0.01)$ when compared to cocultures containing $1 \times 10^{3}$ cells/well. These results suggest that cMSCs from synovium, marrow, and adipose tissues are capable of 

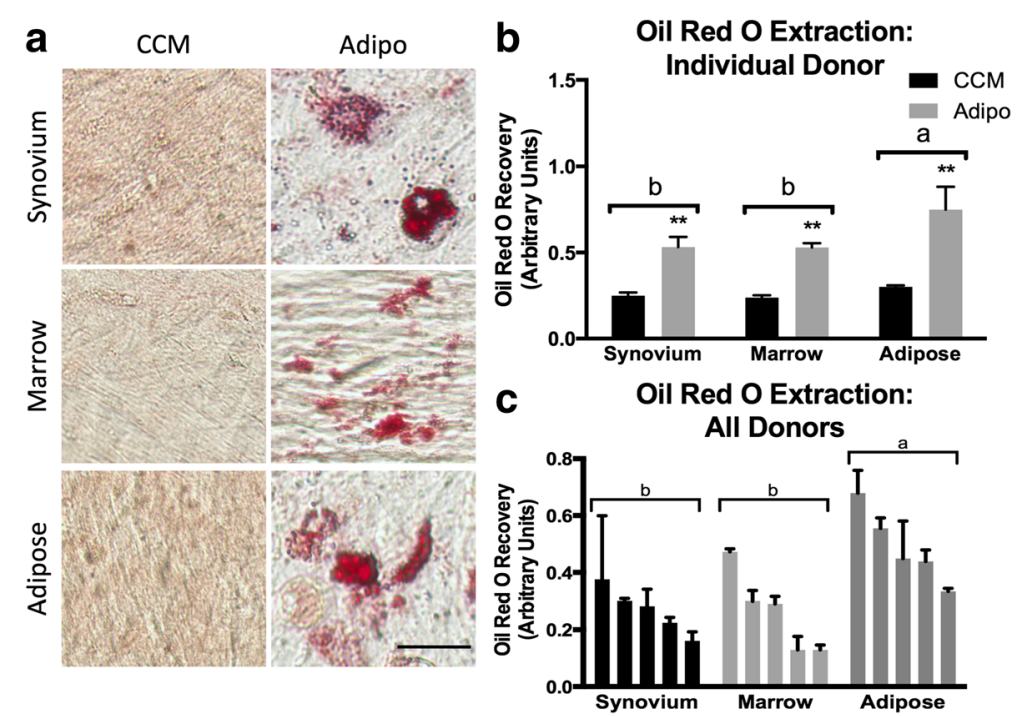

Fig. 5 Adipogenesis of synovium, marrow, and adipose of CMSCs. a Passage 2 CMSCs were cultured in quadruplicate wells in CCM or modified adipogenic media with media exchange twice weekly. At 21 days, cells were formalin fixed and evaluated for lipid accumulation with Oil Red $\mathrm{O}$ (bar $=25 \mu \mathrm{m}$ ). b Oil Red $\mathrm{O}$ quantification (mean $\pm \mathrm{SD}$ ) for a representative donor. ${ }^{*}$ Significantly different Oil Red $\mathrm{O}$ quantification between treatment conditions $(p<0.01)$. c Mean \pm SD Oil Red O quantification for all 15 CMSC isolates. CCM values have been subtracted from adipogenic values to facilitate data presentation. Data are reported in descending order for each tissue. For $\mathbf{b}$ and $\mathbf{c}, a, b$ denote significant differences between tissue sources of CMSCS $(p<0.001)$. CCM complete culture medium

modulating macrophage-mediated inflammation in the described in-vitro coculture system, specifically via modulation of murine TNF- $\alpha$.

Interestingly, while TNF- $\alpha$ concentrations decreased in response to cMSC coculture, the concentration of murine IL-6 increased in the LPS coculture assay (Additional file 3). The increased concentration of detected IL-6 was not due to cross-reactivity with canine IL-6, because we were unable to detect any IL-6 signal in conditioned media from cMSCs cultured in the absence of murine macrophages (data not shown) and the fact that the selected ELISA is specific for murine IL-6. Cocultures of murine macrophages and canine adipose-derived cMSCs contained significantly higher concentrations of IL-6 when compared to the other tissue types $(p<0.001)$. Collectively, these results indicate that cMSCs are indeed capable of affecting an LPS-mediated inflammatory response in the in-vitro setting, and that when cocultured with cMSCs murine macrophages appear to differentially modulate TNF- $\alpha$ and IL-6.

\section{Discussion}

While the canine species represents a strong model for translation of cell-based treatments from laboratory animals to humans, selecting the ideal tissue source from which to isolate canine MSCs for specific applications remains a challenge. This challenge exists due to the modest number of publications focused on canine MSCs, donor variation across studies, and the widely variable cell isolation, culture, and differentiation protocols used by different groups of investigators. Importantly, authors of existing canine MSC characterization studies for the most part utilized differentiation protocols developed for human MSCs, despite evidence that these protocols in some instances may lead to inconsistent differentiation of canine MSCs [34, 51, $52,59,61,74,75]$. For example, canine MSCs have been shown to be more prone to monolayer detachment in late-stage osteogenic cultures [30, 34, 51, 60, 61, 74], a property we observed during our initial work with canine MSCs. In contrast to human MSCs, in the in-vitro setting, canine MSCs have also been shown to require BMP-2 supplementation for consistent early osteogenic differentiation [52, 75], a finding confirmed in the present study (Fig. 6). With regard to adipogenesis, some authors have described supplementing adipogenic differentiation media with varying concentrations of pantothenate, biotin, rosiglitazone, and rabbit serum to improve the consistency of cMSC adipogenesis [30, 34, 53, 74]. Finally, while the immunomodulatory effects of MSCs have received much attention in other species [77-84, 104-108], only a handful of studies have examined the immunomodulatory potential of canine MSCs [66, 76, 85-88]. As such, immunomodulatory potential of canine MSCs has not typically been included in donor-matched, canine MSC characterization studies involving larger cohorts of dogs.

Synovium, marrow, and adipose tissue were selected for comprehensive characterization because of the strong clinical interest in these tissues, the likely use of 


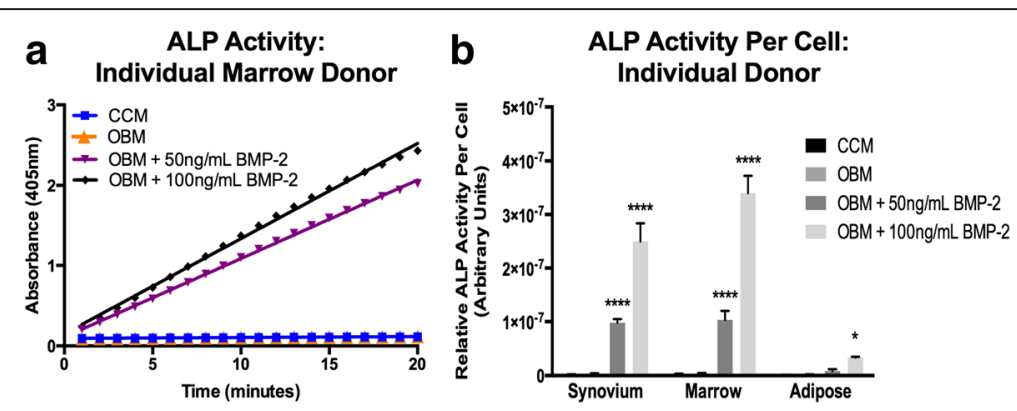

C

ALP Activity: All Donors

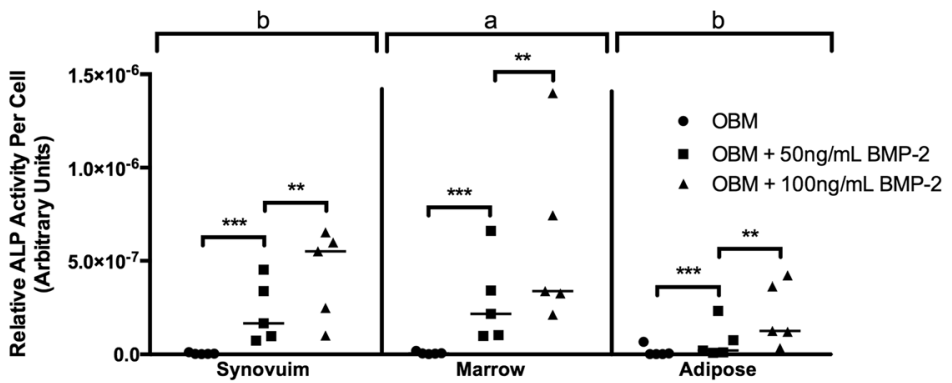

Fig. 6 Early osteogenesis of synovium, marrow, and adipose CMSCS. Early osteogenesis was determined using the alkaline phosphatase (ALP) activity assay. Passage 2 cMSCs were cultured in CCM, OBM, or OBM + rhBMP-2 for 7 days and evaluated for the ability to convert the colorless substrate PNPP to colorimetric PNP over time. a Kinetic ALP activity results for a single CMSC preparation from a representative donor. ALP activity was determined by spectrophotometer (absorbance $405 \mathrm{nM}$ ) over a 20-minute time course. b ALP activity normalized to cell number by DNA quantification for synovium, marrow, and adipose CMSCs from a representative donor, demonstrating the minimal response of adipose CMSCs to OBM or OBM containing rhBMP-2. c Scatter plots demonstrating ALP activity for all 15 CMSC preparations organized by tissue and media condition. Each data point represents the ALP activity per cell for an individual CMSC preparation and a given media condition (bar = mean across the five donors). For $\mathbf{b}$ and $\mathbf{c}$, significant differences between treatment groups: ${ }^{*} p<0.05,{ }^{* *} p<0.01,{ }^{* * *} p<0.001,{ }^{* * * *} p<0.0001 . a, b$ denote significant differences between tissue sources of cMSCs $(p<0.01)$. BMP-2 bone morphogenic protein-2, CCM complete culture medium, OBM osteogenic basal medium

cMSCs from these tissues in future translational studies, the ability to acquire these tissues using minimally invasive techniques (bone marrow aspiration and arthroscopy), and the ability of these tissues to produce robust numbers of MSCs in other species. Canine MSCs were successfully isolated from each of the synovium, marrow, and adipose tissue samples obtained from the five canine donors. Canine MSCs were spindle-shaped, adherent to tissue culture plastic, expressed genes associated with pluripotency, and demonstrated colony forming unit (CFU) potential. While these 15 preparations of cMSC met established criteria for human MSCs [37], there were important differences in the number of nucleated cells isolated from the tissues, CFU potential, flow cytometry profile, proliferation rate, trilineage differentiation, and, to a lesser extent, immunomodulatory properties of cMSCs.

Consistent with previous work in humans $[28,109,110]$, digests of canine synovium/subsynovial tissue produced large numbers of nucleated cells that exhibited significantly higher CFU potential (6.5\%) when compared to marrow $(0.01 \%)$ or adipose tissue digests (2.6\%) (Table 2). Although at present canine synovium has received little attention as a source of MSCs for translational research [111-114], results of the present study demonstrate that canine synovium contains high numbers of MSCs which compare favorably to adipose and marrow-derived cMSCs in the in-vitro setting. In fact, canine synovium exhibited the highest CFU potential of the three examined tissues. Synovium-derived cMSC proliferation was only slightly more attenuated than that of adipose-derived cMSCs and was more rapid than marrow cMSCs. The cells also possessed similar immunomodulatory activity. In differentiation assays, synovium-derived cMSCs performed in a manner similar to marrow-derived cMSCs. These cells underwent robust early-stage and late-stage osteogenesis and adipogenesis, and formed spherical pellets in chondrogenic assays that were larger than marrowderived pellets and similar to adipose-derived pellets. Toluidine blue staining and collagen type II immunohistochemistry demonstrated reduced proteoglycan and collagen type II staining as compared to marrowderived pellets but subjectively increased collagen type II staining when compared to adipose-derived cMSC chondrogenic cultures. Collectively, these results demonstrate that canine synovium is an attractive source for harvesting MSCs in future studies. 


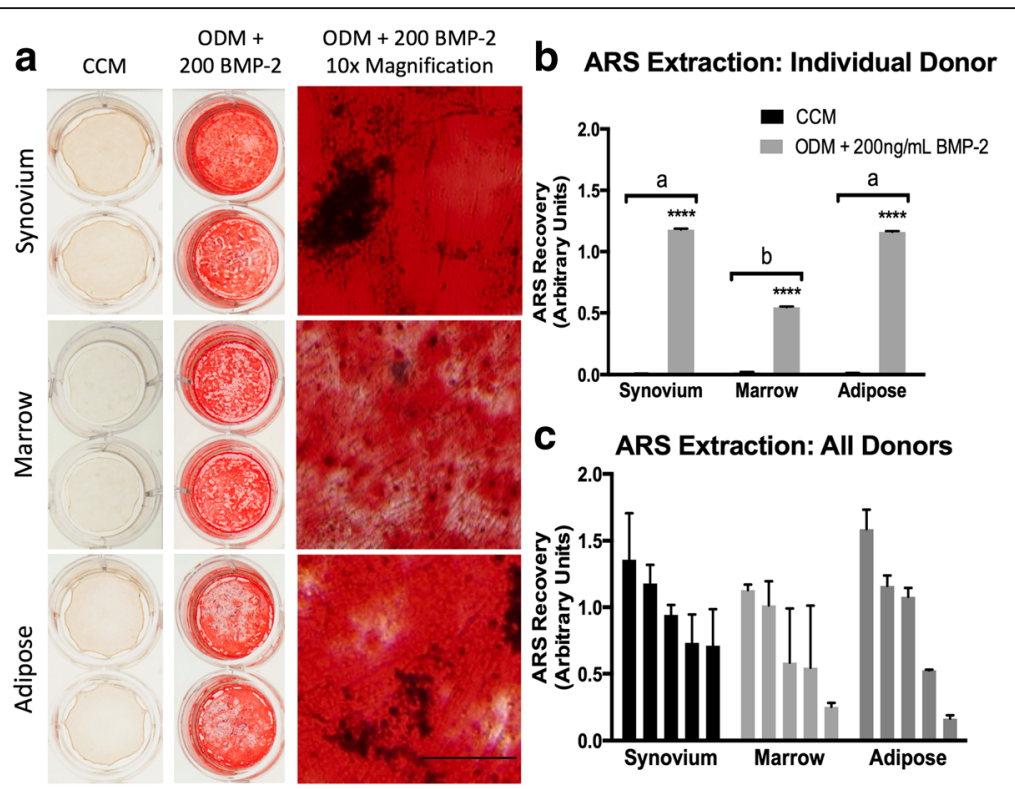

Fig. 7 Late-stage osteogenesis of synovium, marrow, and adipose cMSCs. Passage 2 cMSCs were cultured in triplicate wells in CCM or ODM with media exchange twice weekly. a After 21 days of culture in CCM (left column) or ODM $+200 \mathrm{ng} / \mathrm{ml}$ of rhBMP-2 (middle and right columns) monolayers were fixed in 10\% formalin and stained with ARS. Plates were photographed (left and middle columns) and imaged with 10x objective light microscopy (right column) to document ARS accumulation (bar $=125 \mu \mathrm{m}$ ). b ARS extraction (mean \pm SD) for a representative donor. ****Significant differences between treatment groups $(p<0.0001)$. c Mean \pm SD ARS extraction values for all 15 cMSC preparations. CCM values were subtracted from osteogenic values to facilitate presentation of results. Data are reported in descending order for each tissue. For $\mathbf{b}$ and $\mathbf{c}, a, b$ denote significant differences between tissue sources of CMSCs, if present $(p<0.0001)$. ARS Alizarin Red stain, BMP-2 bone morphogenic protein-2, CCM complete culture medium, ODM osteogenic differentiation medium

A relative consensus currently exists regarding the flow cytometry profile for human MSCs [37]. Unfortunately, a consensus regarding an acceptable flow cytometry profile remains to be determined for canine MSCs. However, our basic flow cytometry results are similar to previous cMSC studies, which for the most part describe canine MSCs as consistently $\mathrm{CD} 45^{-}, \mathrm{CD}^{+}$, and $\mathrm{CD} 44^{+}$ $[29,34,73,74,76,85,89,115,116]$. The canine MSC preparations evaluated in the present study were consistently $\mathrm{CD} 34^{-}, \mathrm{CD} 45^{-}, \mathrm{CD}^{+}, \mathrm{CD} 44^{+}$, and $\mathrm{CD} 90^{+}$. Our flow cytometry profiling did reveal two interesting findings worthy of discussion. First, the 15 preparations of cMSCs in the present study exhibited extremely low STRO-1 levels. The antigen recognized by the STRO-1 antibody is a component of heat shock cognate 80 (HSC70;HSPA8) [117]. In previous canine MSC literature, a single study defined canine marrow-derived MSCs as positive for STRO-1 [62]. Additionally, Whitworth et al. [70] utilized immunocytochemistry to document STRO-1 in canine iPS-MSCs and primary bone marrow MSCs. While STRO-1 has been linked to colony-forming osteogenic progenitor cells in humans $[118,119]$, Jhin et al. [120] demonstrated that canine MSCs from periodontal ligament, alveolar bone, and bone marrow were negative for STRO-1. This finding is consistent with Sakaguchi et al. [28], who reported extremely low STRO-1 levels in human synovium-derived
MSCs. Explanations for variable STRO-1 staining include the rapid loss of STRO-1 during isolation and culture [121] and/or an inherently variable STRO-1 expression in MSCs isolated from different tissues [31, $38,122,123]$.

Second, CD105 (Endoglin) expression varied dramatically when evaluated based on the tissue of origin of cMSCs. The values for our five canine donors varied from $46.1 \pm 21.8 \%$ for synovium, $17.1 \pm 8.8 \%$ for marrow, and $59.8 \pm 16.6 \%$ for adipose-derived cMSCs (Fig. 2, Additional file 2). CD105 is a high affinity coreceptor for transforming growth factor (TGF)- $\beta 1$ and TGF- $\beta 3$ [124]. Canine MSCs have been shown to express CD105 $[70,72,74,115]$. Although CD105 is considered an important MSC marker linked to trilineage differentiation potential in human cells [37, 125, 126], many studies have demonstrated that CD105 expression levels vary substantially based on the tissue source of MSCs, duration in culture, and differentiation status [127-132]. Regarding the effect of CD105 on trilineage differentiation, it has been shown that increased expression of CD105 in human and rat synovium-derived MSCs promoted chondrogenesis in vitro [127, 133]. In contrast, Cleary et al. [134] reported that the presence of CD105 had no effect on chondrogenesis in human bone marrow-derived MSCs. In murine adipose-derived MSCs, initial stromal vascular fraction preparations were 


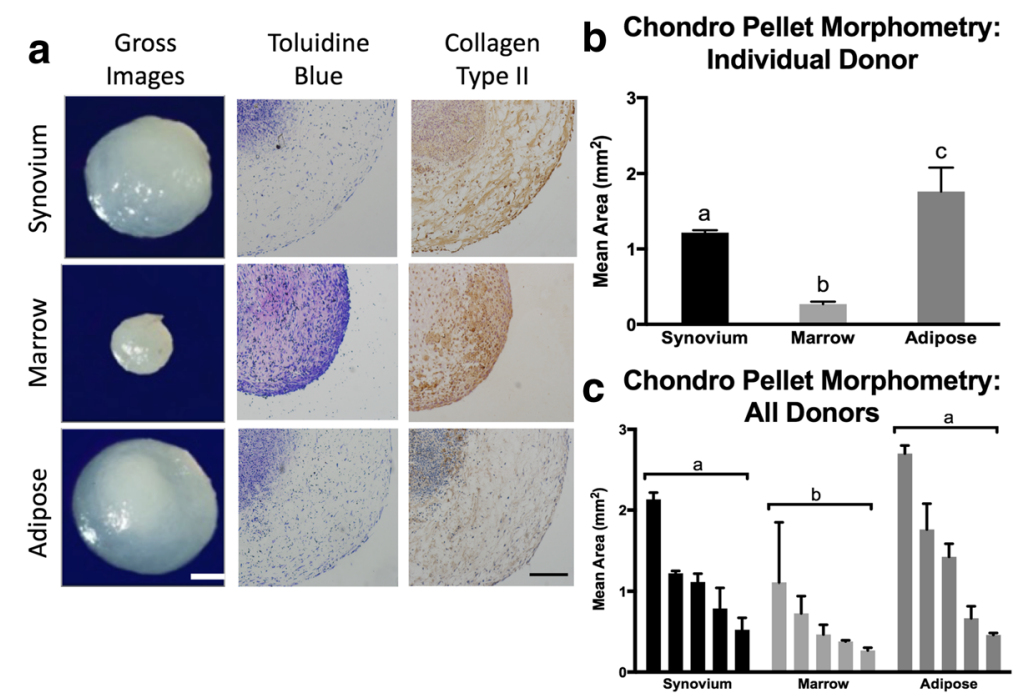

Fig. 8 Chondrogenesis of synovium, marrow, and adipose cMSCs. Passage 2 cMSCs were evaluated for chondrogenesis using the micromass pellet technique: $5 \times 10^{7}$ cells from each cMSC preparation were pelleted in triplicate and incubated for 21 days in chondrogenic medium with media exchange twice weekly. a Pellets were photographed (gross images, bar $=300 \mu \mathrm{m}$ ), formalin fixed, and sectioned for histology. Pellets were positive for proteoglycan (toluidine blue) and collagen type II (10x objective, bar $=150 \mu \mathrm{m}$ ), although the intensity of staining varied across donor and tissue source of cMSC. $\mathbf{b}$ Pellet morphometry for a representative donor (mean \pm SD). c Mean \pm SD pellet area $\left(\mathrm{mm}^{2}\right)$ of chondrogenic pellets for all 15 cMSC preparations. Data are reported in descending order for each tissue. For $\mathbf{b}$ and $\mathbf{c}, a, b, c$ denote significant differences between tissue source of $\operatorname{cMSCs}(p<0.01)$

heterogeneous for CD105 and cells negative for CD105 were capable of forming an osteogenic population [124, 131]. Furthermore, expression of CD105 in murine and human adipose-derived MSCs was induced by exposure of cells to tissue culture plastic and was further affected by passage number and confluence $[131,135]$. These findings are further supported by additional studies in which CD105-negative MSCs exhibited enhanced adipogenic and osteogenic potential due to reduced TGF- $\beta /$ SMAD2 signaling $[136,137]$. Thus, it appears that in some cases CD105-negative MSCs are indeed capable of undergoing trilineage differentiation. Considering these findings, it is not surprising that the cMSCs isolated from three distinct tissue sources and five unique donors demonstrated variable CD105 staining. It is also possible that, due to the fact that our cMSC preparations were created by plating pooled nucleated cells (no single cell sorting), the cMSC preparations contained a low percentage of contaminating fibroblasts. This may also partially explain the variable CD105 and low STRO-1 results. Future studies are warranted to define the mechanism(s) behind our findings. Furthermore, studies in which cMSCs are characterized for additional flow cytometry markers (i.e. CD73) or sorted by CD105 prior to differentiation and immunomodulation experiments are perhaps of importance for investigators interested in maximizing trilineage differentiation for tissue engineering purposes. Interestingly, it was recently reported that both adipose and marrow-derived cMSCs were negative for CD73 [88].
The ability of MSCs to self-renew and rapidly expand in culture is of considerable importance when selecting a potential tissue source for translational studies. As has been described for human MSCs, the nucleated cell fractions obtained from synovium and adipose tissue digests in the present study exhibited significantly greater CFU potential (Fig. 1) and produced approximately six-fold greater numbers of P0 cMSCs when compared to bone marrow (Table 2). It is important to note that the initial seeding density of the primary nucleated cells varied between synovium/adipose $\left(200 \mathrm{cells} / \mathrm{cm}^{2}\right)$ and bone marrow $\left(3 \times 10^{4}\right.$ cells $\left./ \mathrm{cm}^{2}\right)$ based on prior literature $[28$, 138]. Furthermore, the time required to reach $70 \%$ confluence for P0 cells varied substantially from 5 to 12 days for all 15 tissue samples, which is consistent with the time required to isolate PO MSCs in other species. In order to control for both seeding density and the number of days in culture (and thus obtain a more representative head-to-head comparison of the cMSCs), we assessed self-renewal using short-term and long-term proliferation assays (Fig. 4). For all five canine donors, adipose and synovium cMSCs proliferated more rapidly when compared to marrow cMSCs. In our short-term assay, adipose cMSCs proliferated more rapidly than synovium cMSCs, and synovium cMSCs more rapidly than marrow cMSCs, although the latter difference was not statistically significant. Regardless of their source, cMSCs demonstrated substantial proliferation from days 5 to 10 , consistent with the lag phase and logarithmic 

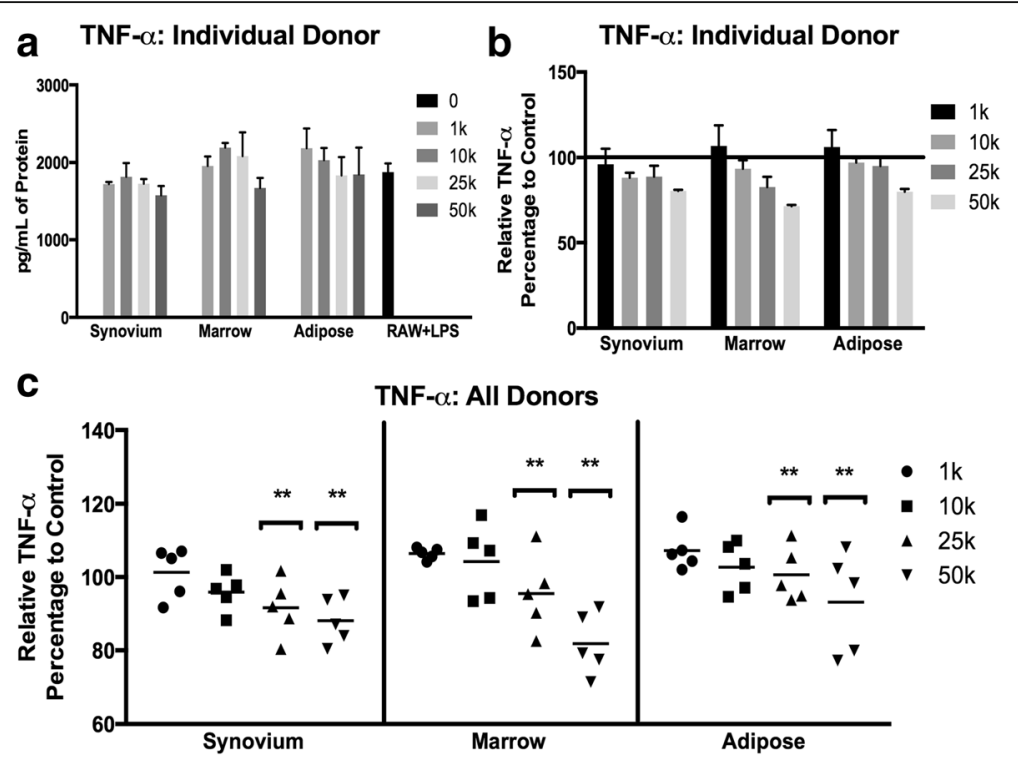

Fig. 9 Immunomodulation of murine TNF-a by synovium, marrow, and adipose cMSCs. Passage $2 \mathrm{cMSCs}\left(1 \times 10^{3}-50 \times 10^{3}\right)$ were cocultured with $1 \times 10^{4}$ murine macrophage cells in 12-well plates in CCM ( $n=3$ wells/condition). After 24 hours, LPS ( $\left.0.5 \mu \mathrm{g} / \mathrm{ml}\right)$ was added to cocultures to activate macrophages. After 18 hours, media were collected and ELISA performed to determine the concentration of secreted murine TNF-a. a Representative murine TNF-a concentrations (mean \pm SD) for an individual donor. RAW + LPS denotes TNF-a concentration from murine macrophages (RAW cells) in the absence of cMSCs (positive control). $\mathbf{b}$ Data from a were transformed to reflect the percentage change in TNF-a relative to the RAW + LPS positive control in preparation for comparative analysis across all 15 cMSC preparations, reported as mean \pm SD. c Scatter plots demonstrating the percentage change of TNF-a concentration relative to positive control for all 15 cMSC preparations, organized by tissue and number of CMSCs present within cocultures. Each data point represents the relative murine TNF-a for an individual cell preparation and "dose" of cMSC (bar = mean across the five donors). For all three tissues, TNF-a concentrations decreased in response to increasing numbers of cocultured cMSCs. Significant differences between numbers of cocultured cMSCs: ${ }^{* *} p<0.01$. LPS lipopolysaccharide, TNF-a tumor necrosis factor alpha

proliferation phases described for human MSCs $[28,96]$. In our long-term passaging assay, population doubling of synovium, marrow, and adipose cMSCs was also significantly different. Population doubling of all cell preparations decreased with subsequent passages. Adipose and synovium cMSCs exhibited significantly higher population doubling rates as compared to marrow cMSCs, which further supports our short-term passaging results. Additionally, the long-term passaging assay confirmed the finite capacity of cMSCs to self-renew, a known property of MSCs in other species. When P0 yield and proliferation results are viewed collectively, our findings suggest that while synovium, bone marrow, and adipose tissues each produce cMSCs, investigators requiring rapid expansion of low-passage cMSCs should consider adipose-derived or synovium-derived cMSCs.

An important criterion of MSCs is the ability to differentiate from a progenitor state down multiple mesenchymal lineages. One of the goals of the present study was to utilize optimized differentiation assays relying heavily on previous canine MSC differentiation literature $[30,52,75]$ and to evaluate trilineage differentiation of cMSCs using a donor-matched study design and multiple canine donors. The methods and results reported herein will prove useful for investigators unfamiliar with
cMSCs, as well as for investigators relying heavily on invitro differentiation results to select a source of cMSCs for translational studies.

Adipogenesis was confirmed in all cell preparations using an optimized adipogenic induction protocol, with slight modifications, as defined by Neupane et al. [30]. Importantly, the morphology and size of lipid vacuoles produced after adipogenesis varied based on the tissue source of cMSCs. Adipose and synovium cMSCs produced classic large, grape-like lipid clusters compared to the small, diffuse vacuoles produced by marrow cMSCs (Fig. 5). These morphologic findings were confirmed by semi-quantification of Oil Red O staining. The superior adipogenic differentiation of adipose-derived MSCs is not surprising due to the pericellular cues that are likely provided to adipose cMSCs in their native environment. Interestingly, synovium performed as an intermediate in adipogenic assays, forming large grape-like lipid vacuoles, but forming them with less frequency when compared to adipose tissue. Differences in the expression and/or regulation of critical adipogenic transcription factors peroxisome proliferator activate receptor gamma (PPAR $\gamma$ ) and CCAAT enhancer-binding protein (C/ $\mathrm{EBP \alpha}$ ), MEK/ERK signaling, turnover or subcellular localization of B-catenin, or downstream effector 
proteins of adipocytes such as AcylCoA synthetase (ACS), lipoprotein lipase (LPL), and fatty acid binding protein 4 (FABP4) are likely to explain our adipogenic results [139-141]. Clearly many additional mechanistic studies evaluating the PPAR $\gamma$ signaling axis and other regulators of adipogenesis are necessary to determine the mechanisms behind our findings.

Osteogenic differentiation of cMSCs was assessed using an early kinetic ALP activity assay and the latestage monolayer ARS mineralization assay. We selected the ALP activity assay because it is a kinetic assay requiring living cells to catabolize an ALP substrate, it has been shown to identify osteogenic differentiation early in the differentiation process [142-144], and it has been evaluated previously in the canine MSC literature. Volk et al. [52] demonstrated that a combination of ascorbate-2-phosphate and rhBMP-2 was necessary to detect ALP activity in early osteogenic marrow-derived cMSC cultures. The results of the present study, in which 15 preparations of cMSCs from three tissue sources were compared, confirm that rhBMP-2 supplementation is necessary to detect ALP activity in early canine osteogenic cultures (Fig. 6). These results demonstrate an important difference between canine and human MSCs which may have in-vivo implications. While none of the cMSCs displayed ALP activity in control (CCM) or basal osteogenic media (OBM) at 7 days of culture, synovium and marrow cMSCs exhibited a strong response to rhBMP-2 as compared to adiposederived MSCs, with marrow exhibiting the highest ALP activity within each donor. Interestingly, the failure of adipose-derived cMSC to respond to BMP-2 supplementation in ALP activity assays described in the present study confirm the findings of Levi et al. [59], in which treatment of canine adipose stromal cells with osteogenic medium supplemented with $200 \mathrm{ng} / \mathrm{ml} \mathrm{rhBMP}-2$ did not increase ALP quantification over baseline. These findings are not surprising given the source of adipose MSCs, and that signaling pathways such as PPAR $\gamma$ compete with osteogenic differentiation pathways such as the canonical Wnt pathway [145-149]. Two potential explanations for the importance of BMP-2 supplementation in canine osteogenesis assays include either speciesspecific differences in bone biology or the loss of canine BMP-2 expression after cMSC isolation, leading to an absence of endogenous canine BMP-2 during in-vitro osteogenesis. In support of these potential explanations, pilot studies in our laboratory revealed that canine BMP-2 is transcribed at an extremely low level under control or traditional osteogenic conditions in early cMSC osteogenic cultures, requiring greater than 35 cycles to reach detection levels using qPCR (unpublished observations). In contrast, human MSCs robustly transcribe BMP-2 under similar conditions [150-153]. In-vivo evidence supporting the relevance of our in-vitro findings also exists. Canine and murine adipose-derived stromal cells seeded on a hydroxyapatite/PLLA scaffold failed to stimulate defect healing in a murine calvarial defect model, whereas human adipose-derived cells initiated significant healing as early as 2 weeks post treatment [59]. In this regard, it is possible that the differentiation pathways underlying canine adipose-derived MSC osteogenic differentiation as well as the ability of adipose cMSCs to contribute to massive bone loss in xenogenic models may more closely resemble murine as opposed to human MSCs.

Using the modified late-stage osteogenesis methods described herein (mechanical scoring of tissue culture surface, precoating with fibronectin, and induction of osteogenesis with a medium containing rhBMP-2), all three tissues produced calcium-binding mineral (Fig. 7). Consistent with the ALP activity results and previous findings of Volk et al. [52, 75], rhBMP-2 supplementation was required for monolayer mineralization. Adipose and synovium cMSCs demonstrated higher ARS recovery values in some donors, although these differences were not significant when evaluated collectively across all donors. Thus, while adipose cMSCs appear to be resistant to early osteogenic differentiation even in the presence of rhBMP-2, our late-stage osteogenesis results suggest that adipose-derived cMSCs are capable of transitioning to osteogenic cultures over time. As such, investigators considering adipose tissue as a source for cMSC osteogenic cells should consider supplementing osteogenic induction media with rhBMP-2 and realize that additional time in culture may be necessary to achieve osteogenic differentiation.

The osteogenic results for synovium cMSCs in our assays were consistent with prior synovium MSC literature [28, 154]. Human synovium-derived MSCs have been shown to exhibit robust ARS stain in late-stage cultures [28], although to our knowledge early osteogenic differentiation of synovium MSCs has not been examined previously using the ALP activity assay in any species. Given the fact that synovium is a robust source of cMSCs, that synovium demonstrates high CFU potential, and that synovium cMSCs undergo both early and latestage osteogenesis, synovium may be considered a strong alternative to bone-marrow-derived cMSCs for investigators requiring rapid production of large numbers of cMSCs with early osteogenic potential. Additionally, we have demonstrated that synovium cMSCs exhibit robust ALP activity in early-stage cultures when treated with osteogenic medium containing rhBMP-2.

In contrast to the adipogenic and osteogenic differentiation assays, the serum-free micromass chondrogenesis technique did not require major modifications for use with cMSCs. All 15 cMSC preparations underwent condensation in response to chondrogenic medium and 
adopted a spherical, translucent appearance classically associated with chondrogenic differentiation. When evaluated histologically, these pellets exhibited both toluidine blue and collagen type II staining, although variability existed based on the tissue source of cMSCs (Fig. 8). Synovium and adipose cMSC produced larger pellets as compared to marrow, but demonstrated subjectively reduced staining for proteoglycan (toluidine blue) and collagen type II when assessed histologically. Despite their small size, marrow-derived chondrogenic pellets were the only cell preparations to consistently exhibit intense staining for proteoglycan (toluidine blue) and collagen type II (immunohistochemistry); however, one obvious limitation regarding the chondrogenic capacity of marrow cMSCs is the reduced pellet size when compared to synovium and adipose cMSCs. Synovium cMSCs provided intermediate chondrogenic results with pellets considerably larger than those produced by marrow cMSCs but containing slightly reduced proteoglycan and collagen type II staining. Adipose cMSCs produced large structures; however, these structures subjectively contained the lowest proteoglycan and collagen type II staining. Admittedly, additional metrics to compare chondrogenic differentiation across donors and tissue types are needed. Future studies in our laboratory that focus solely on chondrogenic differentiation of cMSCs will not only rely on traditional histology and morphometry, but will also utilize quantitative assessment of proteoglycan content and transcriptional activity. The goal of the present study was to provide broad characterization using a donor-matched study design in order to describe general similarities and differences in canine MSCs. Additional quantitative assessments of chondrogenesis for 15 preparations of cMSCs was beyond the scope of the study. Furthermore, additional work is necessary to optimize cMSC chondrogenesis to produce larger micromass pellets with high-intensity staining for proteoglycans and collagen type II for canine translational cartilage repair studies.

In the current MSC field, in order to be considered an MSC, a cell must exhibit immunomodulatory potential. While the immunomodulatory potential of human MSCs is well described, a handful of studies have reported that canine marrow, adipose, and periodontal ligament-derived MSCs are capable of producing growth factors, producing anti-inflammatory cytokines, or directly modulating leukocyte activity or proliferation [66, 76, 85-88]. However, the immunomodulatory potential of synoviumderived cMSCs has yet to be examined and immunomodulatory assays have not been included in large donormatched canine MSC characterization studies. The first description of immunomodulatory potential of cMSCs was provided by Kang et al. [85]. Adipose-derived cMSCs were isolated from a single donor and examined using a comprehensive series of immunomodulatory assays. Adipose cMSCs expressed baseline mRNA for a number of anti-inflammatory proteins, cytokines, and growth factors. The inflammatory cytokine TNF- $\alpha$ decreased in leukocyte and cMSC cocultures, whereas the immunomodulatory agents TGF- $\beta$, hepatocyte growth factor (HGF), prostaglandin E2 (PEG2), and indoleamine 2,3 dioxygenase (IDO) increased. Furthermore, proliferation of stimulated leukocytes was suppressed when cocultured with irradiated cMSCs or with cMSC conditioned media. In support of Kang's findings, Park et al. [87] demonstrated that adipose-derived cMSCs inhibited T-cell proliferation after in-vivo MSC transplantation. With regard to marrowderived cMSCs, Lee et al. [66] reported that canine marrow MSCs were capable of inhibiting leukocyte proliferation and implicated cMSC-derived PGE2 as a potential anti-proliferative factor. Interestingly, while marrow cMSCs displayed in-vitro characteristics similar to MSCs from other species, cMSCs failed to sustain bone marrow engraftment in vivo using a total body irradiation and dog leukocyte antigen (DLA) matched experimental design. In the most comprehensive in-vitro canine immunomodulatory study to date, Chow et al. [88] compared the immunomodulatory properties of adipose and marrow cMSCs from three unrelated dogs. While adipose and marrow cMSCs were roughly equivalent in their ability to suppress T-cell activation, the cMSCs utilized both shared and distinct pathways to accomplish T-cell suppression. An elegant series of coculture experiments and microarrays was used to detail the differences and similarities between adipose and marrow cMSC immunomodulatory potential.

Given the previous studies already detailed, the authors suggest that immunomodulatory assays should be included in characterization assays aimed at confirming canine MSC identity. Moreover, we propose that assessment of immunomodulatory potential should be considered an important metric in comparative characterization studies involving multiple preparations of cMSCs derived from diverse tissues. As such, we aimed to determine whether cMSCs had the capacity to inhibit specific features of the innate immune response and to determine whether the tissue of origin affected this process using a macrophage coculture assay. When murine macrophages were treated with LPS, there was a robust secretion of murine TNF- $\alpha$ that could be detected by ELISA. Inclusion of cMSCs resulted in a significant and dose-dependent decrease in the measured concentration of secreted murine TNF- $\alpha$. Furthermore, this response was observed for all $15 \mathrm{cMSC}$ cell preparations, while the tissue source of cMSCs did not affect the reduction of measured TNF- $\alpha$. The reduction in TNF- $\alpha$ in the present report is consistent with previous adipose-derived cMSC work [85]. To the authors' knowledge, the present study is the first report to confirm that canine synoviumderived cMSCs exhibit immunomodulatory potential. 
It has been described previously that toll-like receptor (TLR) activation is critical for LPS-mediated immunomodulation [155]. However, recent studies describe a noncanonical signaling pathway in which an immune response is elicited without LPS-TLR4 binding [156, 157]. These canonical and noncanonical regulatory mechanisms may be partially responsible for our IL-6 results, namely that inclusion of cMSCs in LPS-stimulated cocultures resulted in an increased concentration of murine IL-6 in coculture conditioned medium. One explanation for increased production of murine IL-6 in response to cMSCs exposed to inflammatory stimuli is the initiation of a proinflammatory pathogen clearance mechanism [158]. This may occur through the NF-kB pathway and PGE production [103, 155]. Additional experiments beyond the scope of the present study are needed to determine the exact regulatory pathways involved in this process.

Despite numerous advantages, limitations of the canine model must also be considered. While many clinically impactful studies have been completed using the canine model, the dog is not traditionally considered to be a common large animal research species. This is particularly the case in societies in which dogs are often considered at a minimum as in-home pets and by some as family members. However, improvements in research protocols to meet changing ethical standards and the adoption of a "one-heath" approach to many medical problems have led to altered perceptions regarding the importance and impact of canine translational studies. For these reasons, the authors suggest that investigators interested in canine clinical models consider collaborating with small animal veterinary clinician scientists or research teams with extensive canine experience. The numerous advantages of these types of collaborative approaches were reviewed recently [25]. While the canine genome has been successfully sequenced, the number of mRNA transcripts that have been sequenced and confirmed as identical to predicted mRNA transcripts is much more modest than in other model species. This may lead to challenges in designing effective PCR primers or siRNAs. Additionally, there is a smaller pool of commercially available reagents capable of crossreacting with the canine species. For example, sourcing antibodies for flow cytometry, immunohistochemistry, and western blotting applications can be a challenge in some instances. Lastly, while the human and dog species share many similarities with regard to skeletal biomechanics, hematopoietic function, and cardiovascular physiology, important differences do exist between these species. The need to supplement canine MSCs with rhBMP-2 for successful early-stage osteogenesis reported in the present study is one such example. Thus, caution should be taken when making assumptions between species or when attempting to translate research findings from one species directly to the other without confirming studies. While in-vitro MSC characterization studies represent a critically important foundation for discovery, differences in cMSC performance in vitro may or may not be relevant to specific disease states in vivo (either spontaneous or induced injury). As with all in-vitro work, the clinical impact of the present study should be confirmed with future studies in which in-vitro cMSC characterization can be directly compared alongside outcomes in vivo.

\section{Conclusions}

We successfully isolated MSCs from canine synovium, marrow, and adipose tissues. While all cMSC preparations exhibited characteristics of MSCs using in-vitro assays optimized for the canine species, both the tissue of origin and the donor impacted cMSC performance. Synovium cMSCs exhibited robust early-stage and late-stage osteogenic differentiation. Combining their ease of isolation, CFU potential, rapid proliferation, immunomodulatory potential, and presence within the intra-articular niche, canine synovium MSCs appear to be an excellent choice for orthopedic translational cell-based studies. While marrow cMSCs had a lower CFU potential and proliferated more slowly, our findings demonstrate that marrow cMSCs were capable of marked early and late-stage osteogenic differentiation and produced chondrogenic pellets that stained intensely for proteoglycan and collagen type II, making marrow an excellent source of cMSCs for orthopedic applications. Given the inability of adipose cMSCs to demonstrate detectible ALP activity even in the presence of substantial BMP-2 supplementation, adipose tissue may not be an ideal source for osteogenic cells if short-term cultures are required; however, adipose tissue produced large numbers of cMSCs with high CFU and proliferation potential. Moreover, adipose cMSCs produced calcium-rich late-stage monolayer osteogenic cultures, and thus may be suitable for investigators interested in long-term culture of tissue engineering constructs. Interestingly, cMSCs isolated from synovium, marrow, and adipose tissue modulated TNF- $\alpha$ levels in LPSstimulated macrophage coculture assays, suggesting that the three tissue sources of cMSCs are capable of immunomodulatory activity in the in-vitro setting. Our methods and results provide insight into important similarities and differences between cMSCs and human MSCs, and will prove useful for investigators considering these canine tissues for large animal translational studies.

\section{Additional files}

Additional file 1: Supplemental Materials \& Methods containing a complete/comprehensive description of the materials and methods, which are summarized in the primary manuscript. (DOCX $60 \mathrm{~kb}$ ) 
Additional file 2: Table S1. Presenting flow cytometry results. (DOCX $17 \mathrm{~kb}$ )

Additional file 3: Figure S1. Showing immunomodulation of murine IL-6. (TIFF $427 \mathrm{~kb}$ )

\section{Abbreviations}

ALP: Alkaline phosphatase; ANOVA: Analysis of variance; ARS: Alizarin red stain; AUP: Animal use protocol; BMP-2: Bone morphogenic protein-2; CCM: Complete culture medium; cDNA: Complementary DNA; CFU: Colony forming unit; CMSC: Canine MSC; ELISA: Enzyme-linked immunosorbent assay; FBS: Fetal bovine serum; IACUC: Institutional animal care and use committee; IL-6: Interleukin 6; MSC: Multipotent stromal cell; OBM: Osteogenic basal medium; ODM: Osteogenic differentiation medium; PBS: Phosphate-buffered saline; PD: Population doubling; P-NPP: $p$-Nitrophenyl phosphate; SD: Standard deviation; TLR: Toll-like receptor; TNF-a: Tumor necrosis factor alpha

\section{Acknowledgements}

The authors would like to thank Dr Ann Kier and Dr Frienhelm Schroeder for their assistance with plate reader access as well as Dr Lauren Dobson for assistance with creation of figures.

\section{Funding}

Funding for this work was provided by the American Kennel Club-Canine Health Foundation (AKC-CHF) grant number 02078 and a generous gift to the Bone \& Joint Fund, Texas A\&M Foundation, College Station, TX, USA.

\section{Authors' contributions}

$\mathrm{RNB}$, first author, was responsible for conception and design, collection and assembly of data, data analysis and interpretation, manuscript writing, and final approval of the manuscript. SSH was responsible for collection and assembly of data, and manuscript writing. CAG was responsible for conception and design, data analysis and interpretation, manuscript writing, and final approval of the manuscript. RS was responsible for collection and assembly of data, and manuscript writing. KJC was responsible for data analysis and interpretation, and manuscript writing. WBS was responsible for conception and design, financial support, administrative support, collection and assembly of data, data analysis and interpretation, manuscript writing, and final approval of manuscript. All authors read and approved the final manuscript.

\section{Ethics approval and consent to participate}

The authors declare that informed consent was obtained from all clients/pet owners. This study was performed under the supervision of the Texas A\&M University Institutional Animal Care and Use Committee (IACUC) and the College of Veterinary Medicine \& Biomedical Sciences' Clinical Research Review Committee (CRRC) through an approved Animal Use Protocol (AUP) (2011-149).

\section{Consent for publication}

The authors declare that all data and images presented herein are the original work of the authors.

\section{Competing interests}

The authors declare that they have no competing interests.

\section{Publisher's Note}

Springer Nature remains neutral with regard to jurisdictional claims in published maps and institutional affiliations

\section{Author details}

${ }^{1}$ Department of Small Animal Clinical Sciences, College of Veterinary Medicine and Biomedical Sciences, Texas A\&M University, College Station, TX, USA. ${ }^{2}$ Department of Veterinary Integrative Biosciences, College of Veterinary Medicine and Biomedical Sciences, Texas A\&M University, College Station, TX, USA. ${ }^{3}$ Department of Veterinary Pathobiology, College of Veterinary Medicine and Biomedical Sciences, Texas A\&M University, College Station, TX, USA. ${ }^{4}$ Department of Molecular and Cellular Medicine, Institute for Regenerative Medicine, College of Medicine, Texas A\&M University, College Station, TX, USA.
Received: 18 July 2016 Revised: 6 July 2017

Accepted: 24 July 2017 Published online: 03 October 2017

\section{References}

1. Hatsushika D, Muneta T, Nakamura T, Horie M, Koga H, Nakagawa Y, et al. Repetitive allogeneic intraarticular injections of synovial mesenchymal stem cells promote meniscus regeneration in a porcine massive meniscus defect model. Osteoarthr Cartilage. 2014;22:941-50.

2. Kon E, Muraglia A, Corsi A, Bianco P, Marcacci M, Martin I, et al. Autologous bone marrow stromal cells loaded onto porous hydroxyapatite ceramic accelerate bone repair in critical-size defects of sheep long bones. J Biomed Mater Res. 2000;49:328-37

3. Horie M, Driscoll MD, Sampson HW, Sekiya I, Caroom CT, Prockop DJ, et al. Implantation of allogenic synovial stem cells promotes meniscal regeneration in a rabbit meniscal defect model. J Bone Joint Surg Am. 2012;94:701.

4. Murphy JM, Fink DJ, Hunziker EB, Barry FP. Stem cell therapy in a caprine model of osteoarthritis. Arthritis Rheum. 2003;48:3464-74.

5. Storb R, Epstein RB, Graham TC, Thomas ED. Methotrexate regimens for control of graft-versus-host disease in dogs with allogeneic marrow grafts. Transplantation. 1970;9:240-6.

6. Prentice HG, Blacklock HA, Janossy G, Gilmore MJ, Price-Jones L, Tidman N, et al. Depletion of T lymphocytes in donor marrow prevents significant graft-versus-host disease in matched allogeneic leukaemic marrow transplant recipients. Lancet. 1984;1:472-6.

7. Socié G, Blazar BR. Acute graft-versus-host disease: from the bench to the bedside. Blood Am Soc Hematol. 2009:114:4327-36.

8. Kiviranta I, Tammi M, Jurvelin J, Säämänen AM, Helminen HJ. Moderate running exercise augments glycosaminoglycans and thickness of articular cartilage in the knee joint of young beagle dogs. J Orthop Res. 1988;6:188-95.

9. Bockstahler BA, Skalicky M, Peham C, Müller M, Lorinson D. Reliability of ground reaction forces measured on a treadmill system in healthy dogs. Vet J. 2007;173:373-8.

10. Bergmann G, Siraky J, Rohlmann A, Koelbel R. A comparison of hip joint forces in sheep, dog and man. J Biomech. 1984;17:907-21.

11. Liebschner MAK. Biomechanical considerations of animal models used in tissue engineering of bone. Biomaterials. 2004;25:1697-714

12. Brandt KD, Braunstein EM, Visco DM, O'Connor B, Heck D, Albrecht M. Anterior (cranial) cruciate ligament transection in the dog: a bona fide model of osteoarthritis, not merely of cartilage injury and repair. J Rheumatol. 1991;18:436-46.

13. Liu W, Burton-Wurster N, Glant TT, Tashman S, Sumner DR, Kamath RV, et al. Spontaneous and experimental osteoarthritis in dog: similarities and differences in proteoglycan levels. J Orthop Res. 2003;21:730-7.

14. Shortkroff S, Barone L, Hsu HP, Wrenn C, Gagne T, Chi T, et al. Healing of chondral and osteochondral defects in a canine model: the role of cultured chondrocytes in regeneration of articular cartilage. Biomaterials. 1996;17:147-54

15. Nelson BH, Anderson DD, Brand RA, Brown TD. Effect of osteochondral defects on articular cartilage. Contact pressures studied in dog knees. Acta Orthop Scand. 1988;59:574-9.

16. Arnoczky SP, Warren RF. The microvasculature of the meniscus and its response to injury. An experimental study in the dog. Am J Sports Med. 1983;11:131-41.

17. Johnson EE, Urist MR, Schmalzried TP, Chotivichit A, Huang HK, Finerman GA. Autogeneic cancellous bone grafts in extensive segmental ulnar defects in dogs. Effects of xenogeneic bovine bone morphogenetic protein without and with interposition of soft tissues and interruption of blood supply. Clin Orthop Relat Res. 1989;243:254-65.

18. Pozzi A, Kim SE, Conrad BP, Horodyski M, Banks SA. Ex vivo pathomechanics of the Canine Pond-Nuki Model. Plos One. 2013;8:e81383-6. Wade C, editor.

19. Pond MJ, Nuki G. Experimentally-induced osteoarthritis in the dog. Ann Rheum Dis. 1973:32:387-8.

20. Kol A, Arzi B, Athanasiou KA, Farmer DL, Nolta JA, Rebhun RB, et al. Companion animals: Translational scientist's new best friends. Sci Transl Med. 2015;7:308ps21-1

21. Fenger JM, London CA, Kisseberth WC. Canine osteosarcoma: a naturally occurring disease to inform pediatric oncology. ILAR J. 2014;55:69-85.

22. Murphy CJ, Bentley E, Miller PE, Mclntyre K, Leatherberry G, Dubielzig R, et al. The pharmacologic assessment of a novel lymphocyte function-associated antigen-1 antagonist (SAR 1118) for the treatment of keratoconjunctivitis sicca in dogs. Invest Ophthalmol Vis Sci. 2011;52:3174-80. 
23. Honigberg LA, Smith AM, Sirisawad M, Verner E, Loury D, Chang B, et al. The Bruton tyrosine kinase inhibitor $\mathrm{PCl}-32765$ blocks B-cell activation and is efficacious in models of autoimmune disease and B-cell malignancy. Proc Natl Acad Sci U S A. 2010;107:13075-80.

24. Harding J, Roberts RM, Mirochnitchenko O. Large animal models for stem cell therapy. Stem Cell Res Ther. 2013:4:23.

25. Hoffman AM, Dow SW. Concise review: Stem cell trials using companion animal disease models. Stem Cells. 2016;34;1709-129

26. Friedenstein AJ, Gorskaja U, Kulagina N. Fibroblast precursors in normal and irradiated mouse hematopoietic organs. Exp Hematol. 1976;4:267-74.

27. Friedenstein AJ, Chailakhrk, Latsinik N, Panasyuk A, Keilissbiv. Stromal cells responsible for transferring microenvironment of hematopoietic tissues-cloning in vitro and retransplantation in vivo. Transplantation. 1974;17:331-40.

28. Sakaguchi Y, Sekiya I, Yagishita K, Muneta T. Comparison of human stem cells derived from various mesenchymal tissues: superiority of synovium as a cell source. Arthritis Rheumatol. 2005:52:2521-9.

29. Takemitsu H, Zhao D, Yamamoto I, Harada Y, Michishita M, Arai T. Comparison of bone marrow and adipose tissue-derived canine mesenchymal stem cells. BMC Vet Res. 2012;8:1-9.

30. Neupane M, Chang C-C, Kiupel M, Yuzbasiyan-Gurkan V. Isolation and characterization of canine adipose-derived mesenchymal stem cells. Tissue Eng Pt A. 2008;14:1007-15.

31. Zuk P, Zhu M, Ashjian P, De Ugarte D, Huang J, Mizuno H, et al. Human adipose tissue is a source of multipotent stem cells. Mol Biol Cell. 2002;13:4279-95

32. Peng $L$, Jia $Z$, Yin $X$, Zhang $X$, Liu $Y$, Chen $P$, et al. Comparative analysis of mesenchymal stem cells from bone marrow, cartilage, and adipose tissue. Stem Cells Dev. 2008;17:761-73.

33. De Bari C, Dell'Accio F, Tylzanowski P, Luyten FP. Multipotent mesenchymal stem cells from adult human synovial membrane. Arthritis Rheum. 2001:44:1928-42

34. Kisiel AH, McDuffee LA, Masaoud E, Bailey TR, Esparza Gonzalez BP, Nino-Fong R. Isolation, characterization, and in vitro proliferation of canine mesenchymal stem cells derived from bone marrow, adipose tissue, muscle, and periosteum. Am J Vet Res. 2012;73:1305-17.

35. De Bari C, Dell'Accio F, Vanlauwe J, Eyckmans J, Khan IM, Archer CW, et al. Mesenchymal multipotency of adult human periosteal cells demonstrated by single-cell lineage analysis. Arthritis Rheum. 2006;54:1209-21.

36. Pierdomenico L, Bonsi L, Calvitti M, Rondelli D, Arpinati M, Chirumbolo $\mathrm{G}$, et al. Multipotent mesenchymal stem cells with immunosuppressive activity can be easily isolated from dental pulp. Transplantation. 2005; 80:836-42.

37. Dominici M, Le Blanc K, Mueller I, Slaper-Cortenbach I, Marini FC, Krause DS, et al. Minimal criteria for defining multipotent mesenchymal stromal cells. The International Society for Cellular Therapy position statement. Cytotherapy. 2006:8:315-7.

38. Colter DC. Identification of a subpopulation of rapidly self-renewing and multipotential adult stem cells in colonies of human marrow stromal cells. Proc Natl Acad Sci U S A. 2001;98:7841-5.

39. Puetzer JL, Petitte JN, Loboa EG. Comparative review of growth factors for induction of three-dimensional in vitro chondrogenesis in human mesenchymal stem cells isolated from bone marrow and adipose tissue. Tissue Eng B Rev. 2010;16:435-44.

40. Stewart MC, Stewart AA. Mesenchymal stem cells: characteristics, sources, and mechanisms of action. Vet Clin North Am Equine Pract. 2011;27:243-61.

41. Arnhold S, Goletz I, Klein H, Stumpf G, Beluche L, Rohde C, et al. Isolation and characterization of bone marrow-derived equine mesenchymal stem cells. Am J Vet Res. 2007;68:1095-105.

42. Vidal M, Kilroy G, Lopez M, Johnson J, Moore R, Gimble J. Characterization of equine adipose tissue-derived stromal cells: adipogenic and osteogenic capacity and comparison with bone marrow-derived mesenchymal stromal cells. Vet Surg. 2007;36:613-22.

43. Niemeyer P, Fechner K, Milz S, Richter W, Suedkamp NP, Mehlhorn AT, et al. Comparison of mesenchymal stem cells from bone marrow and adipose tissue for bone regeneration in a critical size defect of the sheep tibia and the influence of platelet-rich plasma. Biomaterials. 2010;31:3572-9.

44. Yoshimura H, Muneta T, Nimura A, Yokoyama A, Koga H, Sekiya I. Comparison of rat mesenchymal stem cells derived from bone marrow, synovium, periosteum, adipose tissue, and muscle. Cell Tissue Res. 2006;327:449-62.
45. Nishimura K, Solchaga LA, Caplan Al, Yoo JU, Goldberg VM, Johnstone B. Chondroprogenitor cells of synovial tissue. Arthritis Rheum. 1999:42:2631-7.

46. Phinney DG. Isolation of mesenchymal stem cells from murine bone marrow by immunodepletion. Methods Mol Biol. 2008:449:171-86.

47. Pereira R, Halford K, Ohara M, Leeper D, Sokolov B, Pollard M, et al. Cultured adherent cells from marrow can serve as long-lasting precursor cells for bone, cartilage, and lung in irradiated mice. Proc Natl Acad Sci U S A. 1995;92:4857-61.

48. DiGirolamo C, Stokes D, Colter D, Phinney D, Class R, Prockop D. Propagation and senescence of human marrow stromal cells in culture: a simple colonyforming assay identifies samples with the greatest potential to propagate and differentiate. Br J Haematol. 1999;107:275-81.

49. Pittenger M, Mackay A, Beck S, Jaiswal R, Douglas R, Mosca J, et al. Multilineage potential of adult human mesenchymal stem cells. Science. 1999;284:143-7.

50. Dennis J, Merriam A, Awadallah A, Yoo J, Johnstone B, Caplan A. A quadripotential mesenchymal progenitor cell isolated from the marrow of an adult mouse. J Bone Miner Res. 1999;14:700-9.

51. Kadiyala S, Young R, Thiede M, Bruder SP. Culture expanded canine mesenchymal stem cells possess osteochondrogenic potential in vivo and in vitro. Cell Transplant. 1997:6:125-34.

52. Volk S, Diefenderfer D, Christopher S, Haskins M, Leboy P. Effects of osteogenic inducers on cultures of canine mesenchymal stem cells. Am J Vet Res. 2005;66:1729-37.

53. Schwarz C, Leicht U, Rothe C, Drosse I, Luibl V, Röcken M, et al. Effects of different media on proliferation and differentiation capacity of canine, equine and porcine adipose derived stem cells. Res Vet Sci. 2012;93:457-62

54. Reich CM, Raabe O, Wenisch S, Bridger PS, Kramer M, Arnhold S. Isolation, culture and chondrogenic differentiation of canine adipose tissue- and bone marrow-derived mesenchymal stem cells_-a comparative study. Vet Res Commun. 2012;36:139-48.

55. Zhang N, Dietrich MA, Lopez MJ. Canine intra-articular multipotent stromal cells (MSC) from adipose tissue have the highest in vitro expansion rates, multipotentiality, and MSC immunophenotypes. Vet Surg. 2013:42:137-46.

56. Guercio A, Di Bella S, Casella S, Di Marco P, Russo C, Piccione G. Canine mesenchymal stem cells (MSCs): characterization in relation to donor age and adipose tissue-harvesting site. Cell Biol Int. 2013;37:789-98.

57. Csaki C, Matis U, Mobasheri A, Shakibaei M. Co-culture of canine mesenchymal stem cells with primary bone-derived osteoblasts promotes osteogenic differentiation. Histochem Cell Biol. 2008;131:251-66.

58. Kamishina H, Farese JP, Storm JA, Cheeseman JA, Clemmons RM. The frequency, growth kinetics, and osteogenic/adipogenic differentiation properties of canine bone marrow stromal cells. In Vitro Cell Dev Biol Anim. 2008:44:472-9.

59. Levi B, Nelson ER, Brown K, James AW, Xu D, Dunlevie R, et al. Differences in osteogenic differentiation of adipose-derived stromal cells from murine, canine, and human sources in vitro and in vivo. Plast Reconstr Surg. 2011;128:373-86.

60. Spencer ND, Chun R, Vidal MA, Gimble JM, Lopez MJ. In vitro expansion and differentiation of fresh and revitalized adult canine bone marrowderived and adipose tissue-derived stromal cells. Vet J. 2012;191:231-9.

61. Chung D-J, Hayashi K, Toupadakis CA, Wong A, Yellowley CE. Osteogenic proliferation and differentiation of canine bone marrow and adipose tissue derived mesenchymal stromal cells and the influence of hypoxia. Res Vet Sci. 2012;92:66-75

62. Hodgkiss-Geere HM, Argyle DJ, Corcoran BM, Whitelaw B, Milne E, Bennett $D$, et al. Characterisation and differentiation potential of bone marrow derived canine mesenchymal stem cells. Vet J. 2012;194:1-8.

63. Requicha JF, Viegas CA, Albuquerque CM, Azevedo JM, Reis RL, Gomes ME. Effect of anatomical origin and cell passage number on the stemness and osteogenic differentiation potential of canine adipose-derived stem cells. Stem Cell Rev. 2012:8:1211-22.

64. Ock S-A, Maeng G-H, Lee Y-M, Kim T-H, Kumar BM, Lee S-L, et al. Donormatched functional and molecular characterization of canine mesenchymal stem cells derived from different origins. Cell Transplant. 2013:22:2311-21.

65. Screven R, Kenyon E, Myers MJ, Yancy HF, Skasko M, Boxer L, et al. Immunophenotype and gene expression profile of mesenchymal stem cells derived from canine adipose tissue and bone marrow. Vet Immunol Immunopathol. 2014:161:21-31.

66. Lee WS, Suzuki Y, Graves SS, Iwata M, Venkataraman GM, Mielcarek M, et al. Canine bone marrow-derived mesenchymal stromal cells suppress alloreactive lymphocyte proliferation in vitro but fail to enhance engraftment in 
canine bone marrow transplantation. Biol Blood Marrow Transplant. 2011:17:465-75.

67. Alves EG, Serakides RR, Boeloni JN, Rosado IR, Ocarino NLM, Oliveira HP, et al. Comparison of the osteogenic potential of mesenchymal stem cells from the bone marrow and adipose tissue of young dogs. BMC Vet Res. 2014;10:1-9.

68. Bertolo A, Steffen F, Malonzo-Marty C, Stoyanov J. Canine mesenchymal stem cell potential and the importance of dog breed: implication for cellbased therapies. Cell Transplant. 2015;24:1969-80.

69. Zhu X, Yuan F, Li H, Zheng Y, Xiao Y, Yan F. Evaluation of canine mone marrow-derived mesenchymal stem cells after long-term cryopreservation. Zool Sci. 2013;30:1032-7.

70. Whitworth DJ, Frith JE, Frith TJR, Ovchinnikov DA, Cooper-White JJ, Wolvetang EJ. Derivation of mesenchymal stromal cells from canine induced pluripotent stem cells by inhibition of the TGF $\beta /$ activin signaling pathway. Stem Cells Dev. 2014;23:3021-33.

71. Lee KS, Kang HW, Lee HT, Kim H-J, Kim C-L, Song J-Y, et al. Sequential subpassage decreases the differentiation potential of canine adipose-derived mesenchymal stem cells. Res Vet Sci. 2014;96:267-75.

72. Park S-B, Seo M-S, Kim H-S, Kang K-S. Isolation and characterization of canine amniotic membrane-derived multipotent stem cells. Plos One. 2012; 7:e44693. Bauer JA, editor.

73. Vieira NM, Brandalise V, Zucconi E, Secco M, Strauss BE, Zatz M. Isolation, characterization, and differentiation potential of canine adipose-derived stem cells. Cell Transplant. 2010;19:279-89.

74. Csaki C, Matis U, Mobasheri A, Ye H, Shakibaei M. Chondrogenesis, osteogenesis and adipogenesis of canine mesenchymal stem cells: a biochemical, morphological and ultrastructural study. Histochem Cell Biol. 2007;128:507-20.

75. Volk SW, Wang Y, Hankenson KD. Effects of donor characteristics and ex vivo expansion on canine mesenchymal stem cell properties: implications for MSC-based therapies. Cell Transplant. 2012;21:2189-200.

76. James AW, Zhang X, Crisan M, Hardy WR, Liang P, Meyers CA, et al. Isolation and characterization of canine perivascular stem/stromal cells for bone tissue engineering. Plos One. 2017;12:e0177308-16. Kerkis I, editor.

77. English K. Mechanisms of mesenchymal stromal cell immunomodulation. Immunol Cell Biol. 2012;91:19-26.

78. Augello A, Kurth TB, De Bari C. Mesenchymal stem cells: a perspective from in vitro cultures to in vivo migration and niches. Eur Cell Mater. 2010;20:121-33.

79. Prockop DJ, Oh JY. Mesenchymal stem/stromal cells (MSCs): role as guardians of inflammation. Mol Ther. 2009;20:14-20.

80. Singer NG, Caplan Al. Mesenchymal stem cells: mechanisms of inflammation. Annu Rev Pathol Mech Dis. 2011;6:457-78.

81. Prockop DJ. Repair of tissues by adult stem/progenitor Cells (MSCs): controversies, myths, and changing paradigms. Mol Ther. 2009;17:939-46.

82. Nauta AJ, Fibbe WE. Immunomodulatory properties of mesenchymal stromal cells. Blood. 2007;110:3499-506.

83. Uccelli A, Moretta L, Pistoia V. Immunoregulatory function of mesenchymal stem cells. Eur J Immunol. 2006;36:2566-73.

84. Rasmusson I. Immune modulation by mesenchymal stem cells. Exp Cell Res. 2006;312:2169-79.

85. Kang JW, Kang K-S, Koo HC, Park JR, Choi EW, Park YH. Soluble factorsmediated immunomodulatory effects of canine adipose tissue-derived mesenchymal stem cells. Stem Cells Dev. 2008;17:681-94.

86. Kim H-S, Kim K-H, Kim S-H, Kim Y-S, Koo K-T, Kim T-I, et al. Immunomodulatory effect of canine periodontal ligament stem cells on allogenic and xenogenic peripheral blood mononuclear cells. J Periodontal Implant Sci. 2010:40:265-70.

87. Park SA, Reilly CM, Wood JA, Chung D-J, Carrade DD, Deremer SL, et al. Safety and immunomodulatory effects of allogeneic canine adipose-derived mesenchymal stromal cells transplanted into the region of the lacrimal gland, the gland of the third eyelid and the knee joint. Cytotherapy. 2013;15:1498-510.

88. Chow L, Johnson V, Coy J, Regan D, Dow S. Mechanisms of immune suppression utilized by canine adipose and bone marrow-derived mesenchymal stem cells. Stem Cells Dev. 2017;26:374-89.

89. Russell KA, Chow NHC, Dukoff D, Gibson TWG, LaMarre J, Betts DH, et al. Characterization and immunomodulatory effects of canine adipose tissueand bone marrow-derived mesenchymal stromal cells. Plos One. 2016;11:e0167442.

90. Pittenger MF. Mesenchymal stem cells from adult bone marrow. Methods Mol Biol. 2008;449:27-44.
91. Pochampally R. Colony forming unit assays for MSCs. Methods Mol Biol. 2008;449:83-91.

92. Schneider CA, Rasband WS, Eliceiri KW. NIH Image to ImageJ: 25 years of image analysis. Nat Methods. 2012;9:671-5.

93. Okui $Y$, Kano R, Maruyama H, Hasegawa A. Cloning of canine toll-like receptor 7 gene and its expression in dog tissues. Vet Immunol Immunopathol. 2008;121:156-60.

94. Krause U, Seckinger A, Gregory CA. Assays of osteogenic differentiation by cultured human mesenchymal stem cells. Totowa: Humana Press; 2011. p. 215-30. Vemuri M, Chase LG, Rao MS, editors.

95. Greenwood SK, Hill RB, Sun JT, Armstrong MJ, Johnson TE, Gara JP, et al. Population doubling: a simple and more accurate estimation of cell growth suppression in the in vitro assay for chromosomal aberrations that reduces irrelevant positive results. Environ Mol Mutagen. 2004;43:36-44.

96. Sekiya I, Larson B, Smith J, Pochampally R, Cui J, Prockop D. Expansion of human adult stem cells from bone marrow stroma: conditions that maximize the yields of early progenitors and evaluate their quality. Stem Cells. 2002;20:530-41.

97. Reger RL, Tucker AH, Wolfe MR. Differentiation and characterization of human MSCs. Methods Mol Biol. 2008;449:93-107.

98. Al-Nbaheen M, Vishnubalaji R, Ali D, Bouslimi A, Al-Jassir F, Megges M, et al. Human stromal (mesenchymal) stem cells from bone marrow, adipose tissue and skin exhibit differences in molecular phenotype and differentiation potential. Stem Cell Rev. 2012;9:32-43.

99. Sekiya I, Vuoristo J, Larson B, Prockop D. In vitro cartilage formation by human adult stem cells from bone marrow stroma defines the sequence of cellular and molecular events during chondrogenesis. Proc Natl Acad Sci U S A. 2002;99:4397-402.

100. Spencer TE, Bartol FF, Bazer FW, Johnson GA, Joyce MM. Identification and characterization of glycosylation-dependent cell adhesion molecule 1-like protein expression in the ovine uterus. Biol Reprod. 1999;60:241-50.

101. Gao H, Wu G, Spencer TE, Johnson GA, Bazer FW. Select nutrients in the ovine uterine lumen. ii. glucose transporters in the uterus and periimplantation conceptuses. Biol Reprod. 2009;80:94-104.

102. Oh JY, Choi H, Lee RH, Roddy GW, Ylostalo JH, Wawrousek E, et al. Identification of the HSPB4/TLR2/NF-KB axis in macrophage as a therapeutic target for sterile inflammation of the cornea. EMBO Mol Med. 2012:4:435-48.

103. Choi H, Lee RH, Bazhanov N, Oh JY, Prockop DJ. Anti-inflammatory protein TSG-6 secreted by activated MSCs attenuates zymosan-induced mouse peritonitis by decreasing TLR2/NF-KB signaling in resident macrophages. Blood. 2011:118:330-8

104. English K, Barry FP, Field-Corbett CP, Mahon BP. IFN- $y$ and TNF-a differentially regulate immunomodulation by murine mesenchymal stem cells. Immunol Lett. 2007;110:91-100.

105. Carrade DD, Lame MW, Kent MS, Clark KC, Walker NJ, Borjesson DL. Comparative analysis of the immunomodulatory properties of equine adultderived mesenchymal stem cells. Cell Med. 2012;4:1-11.

106. Le Blanc K, Tammik L, Sundberg B, Haynesworth SE, Ringdén O. Mesenchymal stem cells inhibit and stimulate mixed lymphocyte cultures and mitogenic responses independently of the major histocompatibility complex. Scand J Immunol. 2003;57:11-20.

107. Götherström C, Ringdén O, Westgren M, Tammik C, Le Blanc K. Immunomodulatory effects of human foetal liver-derived mesenchymal stem cells. Bone Marrow Transplant. 2003;32:265-72.

108. Le Blanc K. Immunomodulatory effects of fetal and adult mesenchymal stem cells. Cytotherapy. 2003;5:485-9.

109. Mochizuki T, Muneta T, Sakaguchi Y, Nimura A, Yokoyama A, Koga H, et al. Higher chondrogenic potential of fibrous synovium- and adipose synoviumderived cells compared with subcutaneous fat-derived cells: distinguishing properties of mesenchymal stem cells in humans. Arthritis Rheum. 2006;54:843-53.

110. Fan J, Varshney RR, Ren L, Cai D, Wang D-A. Synovium-derived mesenchymal stem cells: a new cell source for musculoskeletal regeneration. Tissue Eng B Rev. 2009;15:75-86.

111. Fox DB, Warnock JJ. Cell-based meniscal tissue engineering: a case for synoviocytes. Clin Orthop Relat Res. 2011;469:2806-16.

112. Warnock JJ, Fox DB, Stoker AM, Cook JL. Evaluation of in vitro growth factor treatments on fibrochondrogenesis by synovial membrane cells from osteoarthritic and nonosteoarthritic joints of dogs. Am J Vet Res. 2011;72:500-11. 
113. Spina J, Warnock J, Duesterdieck-Zellmer K, Baltzer W, Ott J, Bay B. Comparison of growth factor treatments on the fibrochondrogenic potential of canine fibroblast-like synoviocytes for meniscal tissue engineering. Vet Surg. 2014;43: 750-60.

114. Innes JF, Gordon C, Vaughan-Thomas A, Rhodes NP, Clegg PD. Evaluation of cartilage, synovium and adipose tissue as cellular sources for osteochondral repair. Vet J. 2013;197:619-24.

115. Kang B-J, Ryu H-H, Park S-S, Koyama Y, Kikuchi M, Woo H-M, et al. Comparing the osteogenic potential of canine mesenchymal stem cells derived from adipose tissues, bone marrow, umbilical cord blood, and Wharton's jelly for treating bone defects. J Vet Sci. 2012;13:299.

116. de Bakker E, Van Ryssen B, De Schauwer C, Meyer E. Canine mesenchymal stem cells: state of the art, perspectives as therapy for dogs and as a model for man. Vet Quart. 2013;33:225-33.

117. Fitter S, Gronthos S, Ooi SS, Zannettino ACW. The mesenchymal precursor cell marker antibody STRO-1 binds to cell surface heat shock cognate 70. Stem Cells. 2017;35:940-51.

118. Gronthos S, Zannettino AC, Graves SE, Ohta S, Hay SJ, Simmons PJ. Differential cell surface expression of the STRO-1 and alkaline phosphatase antigens on discrete developmental stages in primary cultures of human bone cells. J Bone Miner Res. 1999;14:47-56.

119. Gronthos S, Graves SE, Ohta S, Simmons PJ. The STRO-1+ fraction of adult human bone marrow contains the osteogenic precursors. Blood. 1994;84:4164-73.

120. Jhin M-J, Kim Y-S, Kim S-H, Kim K-H, Lee C-W, Koo K-T, et al. Investigation of postnatal stem cells from canine dental tissue and bone marrow. J Korean Acad Periodontol. 2009;39:119-28.

121. Stewart K, Walsh S, Screen J, Jefferiss CM, Chainey J, Jordan GR, et al. Further characterization of cells expressing STRO-1 in cultures of adult human bone marrow stromal cells. J Bone Miner Res. 1999:14:1345-56.

122. Hung S-C, Chen N-J, Hsieh S-L, Li H, Ma H-L, Lo W-H. Isolation and characterization of size-sieved stem cells from human bone marrow. Stem Cells. 2002;20:249-58.

123. Gronthos S, Franklin DM, Leddy HA, Robey PG, Storms RW, Gimble JM Surface protein characterization of human adipose tissue-derived stromal cells. J Cell Physiol. 2001;189:54-63.

124. Yamamoto M, Nakata H, Hao J, Chou J, Kasugai S, Kuroda S. Osteogenic potential of mouse adipose-derived stem cells sorted for CD90 and CD105 in vitro. Stem Cells Int. 2014;2014:576358.

125. Aslan H, Zilberman Y, Kandel L, Liebergall M, Oskouian RJ, Gazit D, et al. Osteogenic differentiation of noncultured immunoisolated bone marrowderived CD105 + cells. Stem Cells. 2006;24:1728-37.

126. Barry FP, Boynton RE, Haynesworth S, Murphy JM, Zaia J. The monoclonal antibody $\mathrm{SH}-2$, raised against human mesenchymal stem cells, recognizes an epitope on endoglin (CD105). Biochem Biophys Res Commun. 1999;265:134-9.

127. Fan W, Li J, Wang Y, Pan J, Li S, Zhu L, et al. CD105 promotes chondrogenesis of synovium-derived mesenchymal stem cells through Smad2 signaling. Biochem Biophys Res Commun. 2016:474:338-44.

128. Gaebel R, Furlani D, Sorg H, Polchow B, Frank J, Bieback K, et al. Cell origin of human mesenchymal stem cells determines a different healing performance in cardiac regeneration. Plos One. 2011;6:e15652.

129. Jiang T, Liu W, Lv X, Sun H, Zhang L, Liu Y, et al. Potent in vitro chondrogenesis of CD105 enriched human adipose-derived stem cells. Biomaterials. 2010;31:3564-71.

130. Jin HJ, Park SK, Oh W, Yang YS, Kim SW, Choi SJ. Down-regulation of CD105 is associated with multi-lineage differentiation in human umbilical cord blood-derived mesenchymal stem cells. Biochem Biophys Res Commun. 2009;381:676-81.

131. Anderson P, Carrillo-Gálvez AB, García-Pérez A, Cobo M, Martín F. CD105 (endoglin)-negative murine mesenchymal stromal cells define a new multipotent subpopulation with distinct differentiation and immunomodulatory capacities. Plos One. 2013;8:e76979. Menendez P, editor.

132. Kern S, Eichler H, Stoeve J, Klüter H, Bieback K. Comparative analysis of mesenchymal stem cells from bone marrow, umbilical cord blood, or adipose tissue. Stem Cells. 2006;24:1294-301.

133. Qi J, Chen A, You H, Li K, Zhang D, Guo F. Proliferation and chondrogenic differentiation of CD105-positive enriched rat synovium-derived mesenchymal stem cells in three-dimensional porous scaffolds. Biomed Mater. 2011;6:015006.
134. Cleary MA, Narcisi R, Focke K, van der Linden R, Brama PAJ, van Osch GJVM. Expression of CD105 on expanded mesenchymal stem cells does not predict their chondrogenic potential. Osteoarthr Cartilage. 2016;24: 868-72.

135. Braun J, Kurtz A, Barutcu N, Bodo J, Thiel A, Dong J. Concerted regulation of CD34 and CD105 accompanies mesenchymal stromal cell derivation from human adventitial tromal cell. Stem Cells Dev. 2013;22:815-27.

136. Levi B, Wan DC, Glotzbach JP, Hyun J, Januszyk M, Montoro D, et al. CD105 protein depletion enhances human adipose-derived stromal cell osteogenesis through reduction of transforming growth factor $\beta 1$ (TGF- $\beta 1$ ) signaling. J Biol Chem. 2011;286:39497-509.

137. Choy L, Skillington J, Derynck R. Roles of autocrine TGF- $\beta$ receptor and Smad signaling in adipocyte differentiation. J Cell Biol. 2000;149:667-82.

138. Wolfe M, Pochampally R, Swaney W, Reger RL. Isolation and culture of bone marrow-derived human multipotent stromal cells (hMSCs). Methods Mol Biol. 2008;449:3-25.

139. Sekiya I, Larson BL, Vuoristo JT, Cui J-G, Prockop DJ. Adipogenic differentiation of human adult stem cells from bone marrow stroma (MSCS). J Bone Miner Res. 2004;19:256-64.

140. Rosen ED, Sarraf P, Troy AE, Bradwin G, Moore K, Milstone DS, et al. PPAR gamma is required for the differentiation of adipose tissue in vivo and in vitro. Mol Cell. 1999;4:611-7.

141. Farmer SR. Regulation of PPARy activity during adipogenesis. Int J Obes Relat Metab Disord. 2005;29:S13-6.

142. Ashton BA, Abdullah F, Cave J, Williamson M, Sykes BC, Couch M, et al. Characterization of cells with high alkaline phosphatase activity derived from human bone and marrow: Preliminary assessment of their osteogenicity. Bone. 1985:6:313-9.

143. Alves H, Dechering K, Van Blitterswijk C, De Boer J. High-throughput assay for the identification of compounds regulating osteogenic differentiation of human mesenchymal stromal cells. Plos One. 2011;6:e26678. Buehler MJ, editor.

144. Brey DM, Motlekar NA, Diamond SL, Mauck RL, Garino JP, Burdick JA. Highthroughput screening of a small molecule library for promoters and inhibitors of mesenchymal stem cell osteogenic differentiation. Biotechnol Bioeng. 2011;108:163-74

145. Krause U, Harris S, Green A, Ylostalo J, Zeitouni S, Lee N, et al. Pharmaceutical modulation of canonical Wnt signaling in multipotent stromal cells for improved osteoinductive therapy. Proc Natl Acad Sci U S A. 2010;107:4147-52.

146. Bennett CN, Ross SE, Longo KA, Bajnok L, Hemati N, Johnson KW, et al. Regulation of Wnt signaling during adipogenesis. J Biol Chem. 2002;277:30998-1004

147. Moldes M, Zuo Y, Morrison RF, Silva D, Park B-H, Liu J, et al. Peroxisomeproliferator-activated receptor gamma suppresses Wnt/beta-catenin signalling during adipogenesis. Biochem J. 2003;376:607-13.

148. Takada I, Kouzmenko AP, Kato S. Molecular switching of osteoblastogenesis versus adipogenesis: implications for targeted therapies. Expert Opin Ther Targets. 2009;13:593-603.

149. Takada I, Kouzmenko AP, Kato S. Wnt and PPARy signaling in osteoblastogenesis and adipogenesis. Nat Rev Rheumatol. 2009;5:442-7.

150. Seib FP, Franke $M$, Jing D, Werner C, Bornhäuser M. Endogenous bone morphogenetic proteins in human bone marrow-derived multipotent mesenchymal stromal cells. Eur J Cell Biol. 2009;88:257-71.

151. Clough BH, McNeill EP, Palmer D, Krause U, Bartosh TJ, Chaput CD, et al. An allograft generated from adult stem cells and their secreted products efficiently fuses vertebrae in immunocompromised athymic rats and inhibits local immune responses. Spine J. 2017;17:418-30.

152. Clough BH, McCarley MR, Krause U, Zeitouni S, Froese JJ, McNeill EP, et al. Bone regeneration with osteogenically enhanced mesenchymal stem cells and their extracellular matrix proteins. J Bone Miner Res. 2015;30: 83-94.

153. Zhang G-P, Zhang J, Zhu C-H, Lin L, Wang J, Zhang H-J, et al. MicroRNA-98 regulates osteogenic differentiation of human bone mesenchymal stromal cells by targeting BMP2. J Cell Mol Med. 2017;21:254-64.

154. Yokoyama A, Sekiya I, Miyazaki K, Ichinose S, Hata Y, Muneta T. In vitro cartilage formation of composites of synovium-derived mesenchymal stem cells with collagen gel. Cell Tissue Res. 2005;322:289-98.

155. Németh K, Leelahavanichkul A, Yuen PST, Mayer B, Parmelee A, Doi K, et al. Bone marrow stromal cells attenuate sepsis via prostaglandin E2-dependent reprogramming of host macrophages to increase their interleukin-10 production. Nat Med. 2009;15:42-9. 
156. Kayagaki N, Wong MT, Stowe IB, Ramani SR, Gonzalez LC, Akashi-Takamura $\mathrm{S}$, et al. Noncanonical inflammasome activation by intracellular LPS independent of TLR4. Science. 2013;341:1246-9.

157. Waterman RS, Tomchuck SL, Henkle SL, Betancourt AM. A new mesenchymal stem cell (MSC) paradigm: polarization into a pro-inflammatory MSC1 or an immunosuppressive MSC2 phenotype. Plos One. 2010;5:10088. Unutmaz D, editor.

158. Bouffi C, Bony C, Courties G, Jorgensen C, Noël D. IL-6-dependent PGE2 secretion by mesenchymal stem cells inhibits local inflammation in experimental arthritis. Plos One. 2010;5:e14247. Agarwal S, editor.

Submit your next manuscript to BioMed Central and we will help you at every step:

- We accept pre-submission inquiries

- Our selector tool helps you to find the most relevant journal

- We provide round the clock customer support

- Convenient online submission

- Thorough peer review

- Inclusion in PubMed and all major indexing services

- Maximum visibility for your research

Submit your manuscript at www.biomedcentral.com/submit
Biomed Central 